\title{
Low Cost, High Efficiency, High Pressure Hydrogen Storage
}

\author{
Final Report \\ May 2004 - December 2009 \\ All Phases Completed \\ Mark Leavitt \\ 9493994584 \\ mleavitt@qtww.com \\ Quantum Technologies Inc. \\ Date Published: March 2010 \\ PREPARED FOR THE UNITED STATES \\ DEPARTMENT OF ENERGY \\ Under Cooperative Agreement \\ No. DE-FC36-04G014010
}

DOE Managers: Katie Randolph, DOE Project Officer

Genevieve Wozniak, DOE Award Administrator

Monterey Gardner, DOE Technology Development Manager 
DE-FC36-04G014010

Quantum Fuel Systems Technologies Worldwide, Inc

\section{Contents}

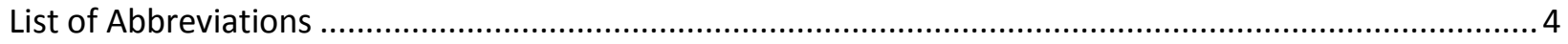

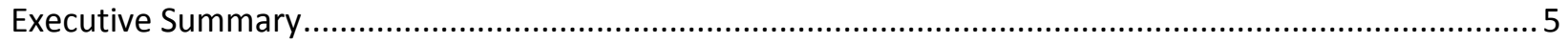

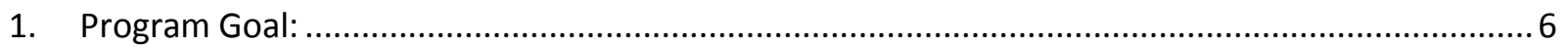

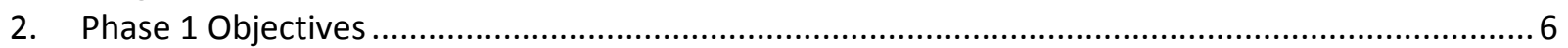

2.1. Track 1 Objective - Composite Optimization ................................................................ 7

2.2. Track 2 Objectives - Tank Instrumentation to Reduce Design Factor of Safety ..................... 8

2.3. Track 3 Objectives - Cool Fuel ....................................................................................... 11

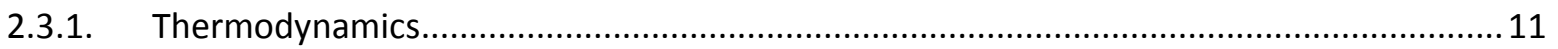

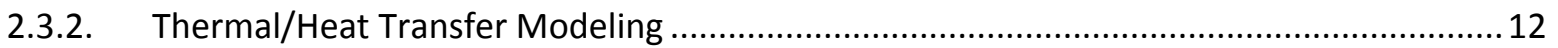

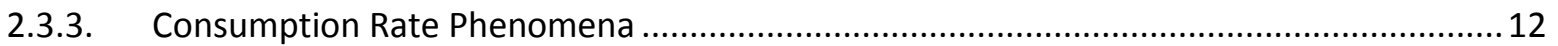

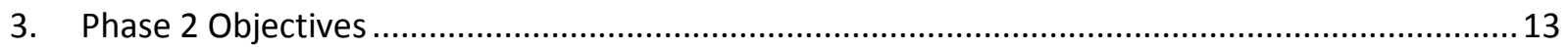

3.1. Track 1 Objectives - Composite Structure Optimization ..................................................... 13

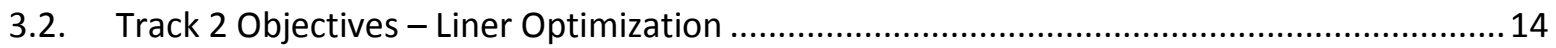

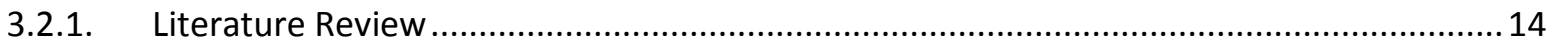

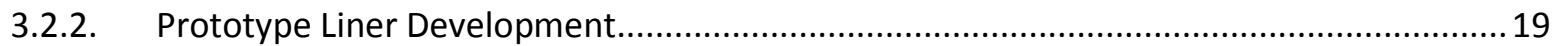

3.2.2.1. PET liner development: Injection stretch blow molding (ISBM) ...................................19

3.2.2.2. PEN liner development: Injection stretch blow molding (ISBM) ................................... 20

3.2.2.3. HDPE Development: Extrusion blow molding (EBM) .............................................. 22

3.2.2.4. Multi-layered structure development: Extrusion blow molding (EBM) ........................23

3.2.2.5. Polyoxymethylene (POM) development: Extrusion blow molding (EBM) .......................2 24

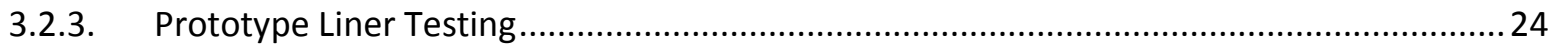

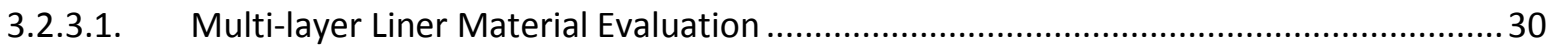

3.2.3.2. Evaluation of the Liners made from Blow Molding Process ........................................ 30

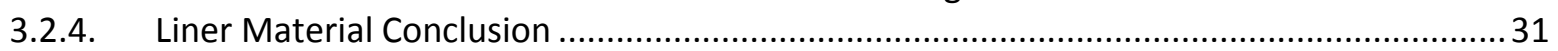

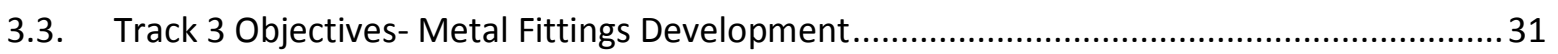

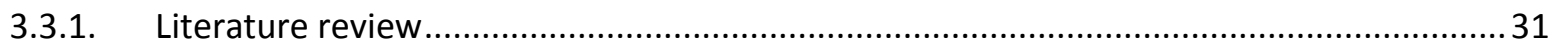

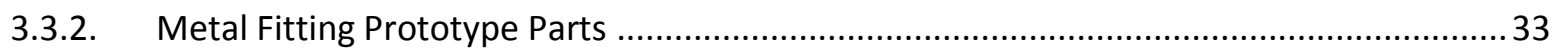

3.4. Composite Manufacturing Process Parameter Optimization .............................................. 34

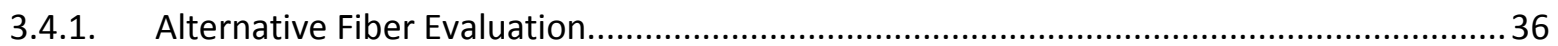

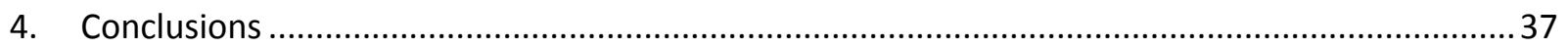

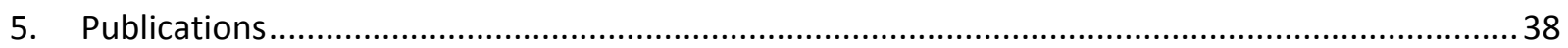

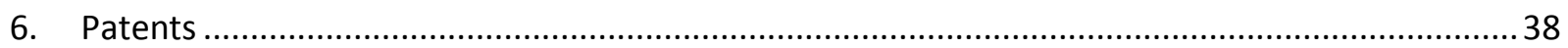

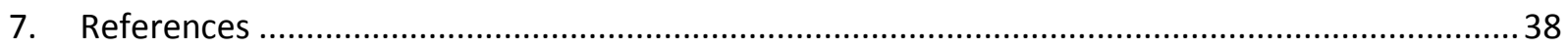


DE-FC36-04G014010

Quantum Fuel Systems Technologies Worldwide, Inc

\section{Tables}

Table 1 - Carbon fiber General Comparison .......................................................................................... 7

Table 2 - Tensile and Izod test comparison between EBM and rotational molded specimens..................23

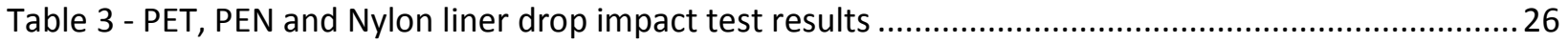

Table 4 - Result of Manufacturing Design of Experiments ................................................................. 35

Table 5 - Progress towards Meeting Technical Targets for On-Board Hydrogen Storage for Light-Duty

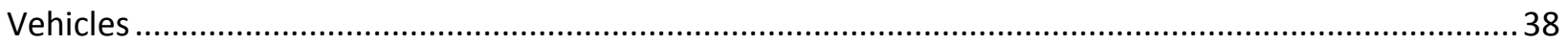

\section{Figures}

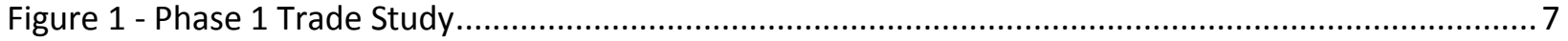

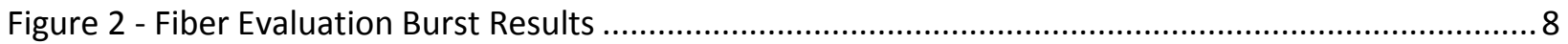

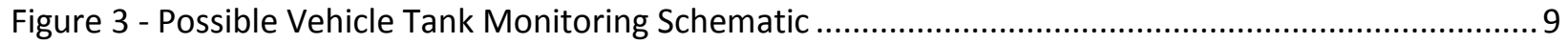

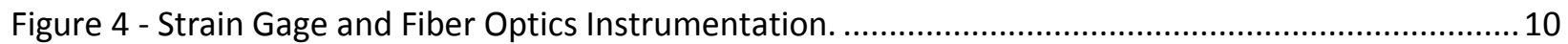

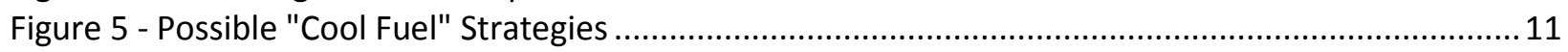

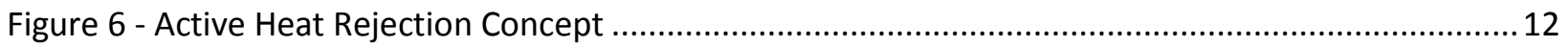

Figure 7 - Selected Strategy for “Cool Fuel” Design.................................................................................. 13

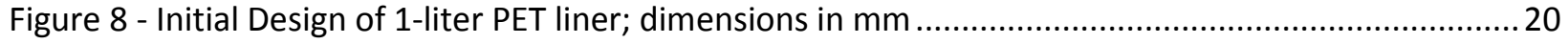

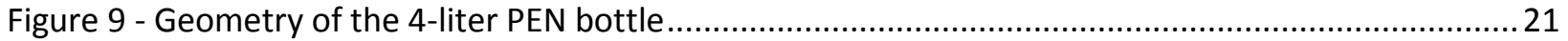

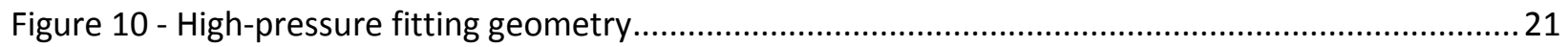

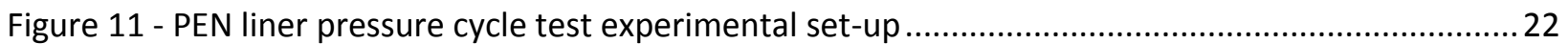

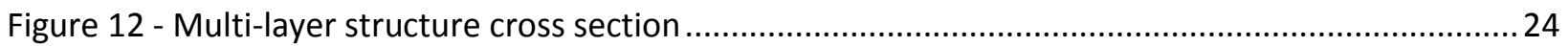

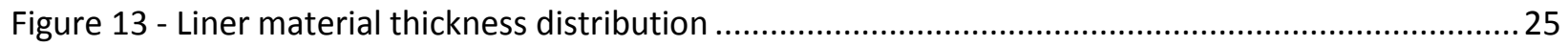

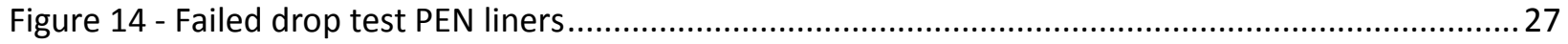

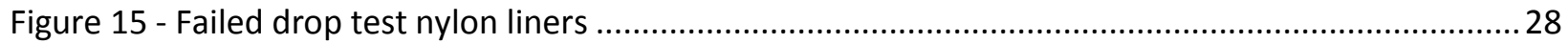

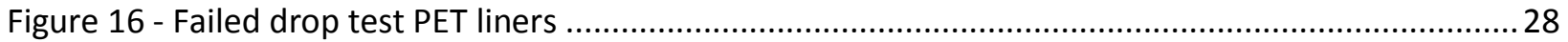

Figure 17 - Liter liner drop test .............................................................. Error! Bookmark not defined.

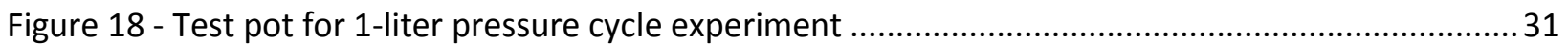

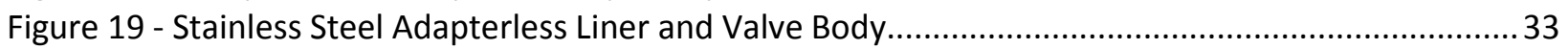

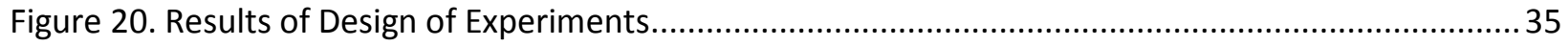

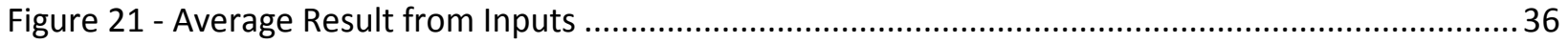


DE-FC36-04G014010

Quantum Fuel Systems Technologies Worldwide, Inc

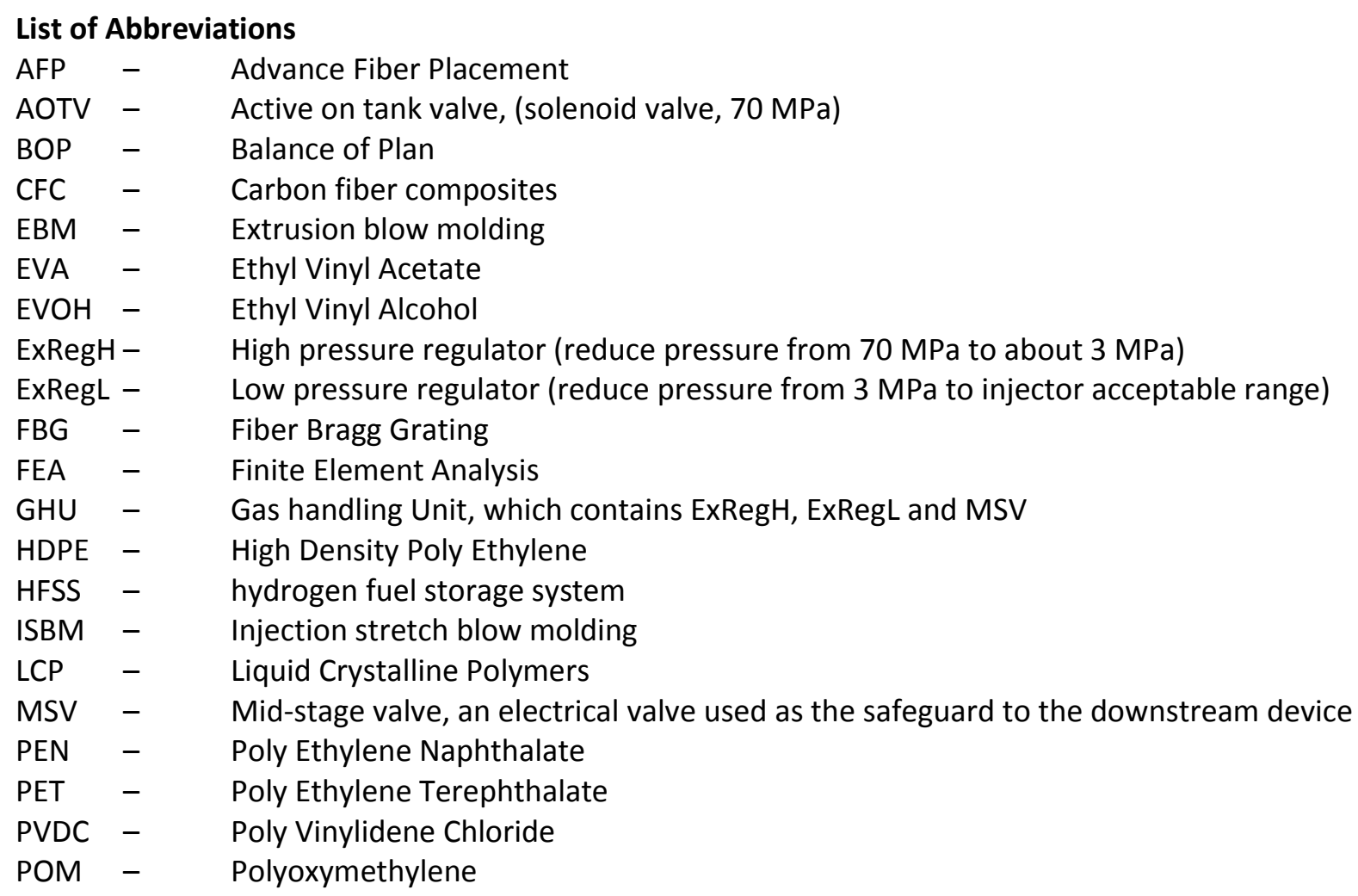


DE-FC36-04G014010

Quantum Fuel Systems Technologies Worldwide, Inc

\section{Executive Summary}

A technical and design evaluation was carried out to meet DOE hydrogen fuel targets for 2010 . These targets consisted of a system gravimetric capacity of $2.0 \mathrm{kWh} / \mathrm{kg}$, a system volumetric capacity of 1.5 $\mathrm{kWh} / \mathrm{L}$ and a system cost of $\$ 4 / \mathrm{kWh}$. In compressed hydrogen storage systems, the vast majority of the weight and volume is associated with the hydrogen storage tank. In order to meet gravimetric targets for compressed hydrogen tanks, 10,000 psi carbon resin composites were used to provide the high strength required as well as low weight. For the 10,000 psi tanks, carbon fiber is the largest portion of their cost.

Quantum Technologies is a tier one hydrogen system supplier for automotive companies around the world. Over the course of the program Quantum focused on development of technology to allow the compressed hydrogen storage tank to meet DOE goals. At the start of the program in 2004 Quantum was supplying systems with a specific energy of 1.1-1.6 kWh/kg, a volumetric capacity of $1.3 \mathrm{kWh} / \mathrm{L}$ and a cost of $\$ 73 / \mathrm{kWh}$. Based on the inequities between DOE targets and Quantum's then current capabilities, focus was placed first on cost reduction and second on weight reduction. Both of these were to be accomplished without reduction of the fuel system's performance or reliability.

Three distinct areas were investigated; optimization of composite structures, development of "smart tanks" that could monitor health of tank thus allowing for lower design safety factor, and the development of "Cool Fuel" technology to allow higher density gas to be stored, thus allowing smaller/lower pressure tanks that would hold the required fuel supply.

The second phase of the project deals with three additional distinct tasks focusing on composite structure optimization, liner optimization, and metal fitting development to lower cost, improve gravimetric efficiency and volumetric efficiency.

\section{1) Optimization of Composite Structure}

Using lower cost fibers was required in order to make significant progress towards cost goals. When Quantum first developed their 10,000 psi tank, aerospace grade fibers were used because of their very high tensile strengths. Aerospace fibers have typical tensile strengths greater than 900,000 psi; however, their price was over $\$ 100 /$ lbs. By the start of this DOE program Quantum had moved to medium cost fibers with tensile strength around $800,000 \mathrm{psi}$ and prices around $\$ 35 / \mathrm{lbs}$. One of the primary goals of the program was to develop the 10,000 psi tank using fibers with tensile strength of 700,000 psi and that cost $\sim \$ 15 /$ lbs. This was the single biggest factor to reduce tank cost. As the tensile strength of the fiber is decreased the weight of the tank is increased. The secondary goal was to improve translation efficiency from approximately $63 \%$ to greater than $80 \%$. Over the course of the program both these goals were achieved and Quantum looked at additional methods to further reduce fiber cost and usage including advance fiber placement, manufacturing design of experiments, and alternative, lower cost fibers.

\section{2) "Smart Tanks"}

"Smart Tank" technologies have been investigated several times over the last 15 years with varying results. Our focus was to look at instrumenting the tank with strain sensors and developing criteria to determine if critical damage had occurred to the tank that would lead to an eventual failure of the composite structure. During the program we looked at different strain monitoring techniques and evaluated their individual strengths and weaknesses. We also looked at the robustness of the composite shell to impact damage and where sensors would have to be placed to detect damage. It was 
DE-FC36-04G014010

Quantum Fuel Systems Technologies Worldwide, Inc

determined that local damage could be detected if the sensor was within 1 to 3 inches of the damage location. It was also determined that the sensors could reliably detect degradation of the composite structure several hundred cycles prior to eventual failure of the tank. From this Quantum estimated that safety factors could be reduced from 2.25 to 1.8 without effecting the overall safety of system. However, after estimating cost for instrumentation of the tank and additional vehicle hardware, a net savings of less than $\$ 1 / \mathrm{kWh}$ would be realized.

\section{3) "Cool Fuel" Technology}

The use of cool fuels involved evaluating storing the hydrogen gas at $-70^{\circ} \mathrm{C}$ in the storage tank, thus increasing the density to a level that would allow smaller tanks, lower pressures, or both. In the study Quantum looked at the fill cycle and storage technology and vehicle dormant issues. For the purpose of the study an in tank heat exchanger was designed and it was assumed that the station would supply low temperature fluid during the fill cycle to offset the heat of compression of the hydrogen tank. Additionally high efficiency insulation was needed on the outside of the tank in order to allow the gas to remain at low temperature and pressure before the need to start venting off excess pressure. The study showed that, like the instrumented tank, by the time additional hardware was added to the tank the net saving was again less than $\$ 1 / \mathrm{kWh}$.

By the end of 2006 Quantum had determined that the "cool fuel" and "smart tank" technology had major technical hurdles and progress towards DOE goals were minimal. Therefore, for the remainder of the program Quantum focused on reducing tank cost and weight by looking at further improvements of composite design, improvements to liner technology and reduction of metal fittings and cost.

Quantum has made significant improvements and has exceeded DOE targets for gravimetric capacity with a value of $2.13 \mathrm{kWh} / \mathrm{kg}$. Also, the cost of a system has been reduced to $\$ 45.9 / \mathrm{kW}$-hr and Quantum is continuing to look at additional methods to reduce cost for production volumes of $\sim 300 \mathrm{k}$ tanks per year. Volumetric capacity has stayed mostly stable over the course of the program because of the requirement to store $129 \mathrm{~L}$ of gas at 10,000 psi. Only minor adjustments have been made to the thickness of the composite shell which has almost no effect on overall system volume.

\section{Program Goal:}

The goal for this project was to validate a commercially viable high performance, compressed hydrogen storage system for transportation applications, in line with DOE storage targets for 2010, focusing on cost reduction and volumetric and gravimetric improvements on the fuel storage system. To accomplish this Quantum focused on improvement of the fuel storage tank in three areas;

- Reduction of weight and cost of the tank through material optimization, process improvement and use of lower cost materials,

- Reduction of carbon fiber usage through the use of "smart sensors" that monitors health of fuel storage system thus allowing lower factor of safety on design,

- Increasing the density of the hydrogen in the storage tank by storing at lower temperatures, allowing smaller tanks to be used to reach range targets.

\section{Phase 1 Objectives}

Phase one consisted of a feasibility study and conceptual design of the fuel storage system focusing on the improvement of the type IV 10,000 psi tank. Phase one is divided into 3 separate tracks (see Figure 1). 


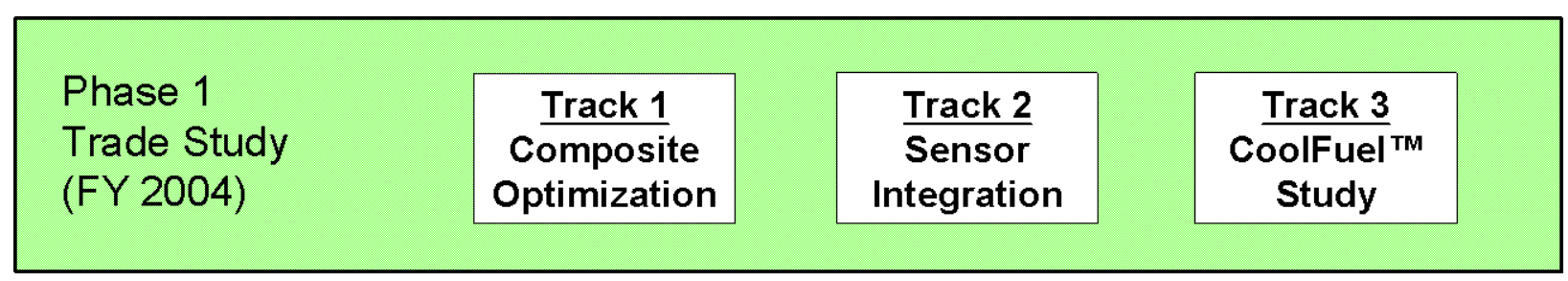

Figure 1 - Phase 1 Trade Study

Track one focused on the optimization of the tank design. At the beginning of the program current 10,000 psi tanks utilized high performance and high cost fibers. These fibers have a tensile strength of approximately $800 \mathrm{ksi}$ and cost around $\$ 58 / \mathrm{kg}$. Additionally fiber translation for 10,000 psi tanks was only $63 \%$. Low translation was due in part to poor consolidation of composite structure on thick walled vessel and loss of fiber performance because of limitations in filament winding.

\subsection{Track 1 Objective - Composite Optimization}

Quantum developed a 28L, 10,000 psi tank as a baseline for cost comparison. This baseline tank was built using medium performance fibers (see Table 1 ). Material costs for the tank were $\$ 2,600$, and the tank held $1.08 \mathrm{~kg}$ of usable hydrogen. Next Quantum characterized low cost fibers tri-axial properties in order to optimize fiber usage. This was accomplished by building small tanks with integrated tri-axial strain gauges throughout the thickness of the composite structure then bursting the tanks. From the results of the burst tests, axisymmetric FEA models were developed for the $28 \mathrm{~L}$ tank using low cost fibers.

Table 1 - Carbon fiber General Comparison

\begin{tabular}{|c|c|c|c|c|c|c|c|c|}
\hline \multirow{2}{*}{ Fiber } & \multirow{2}{*}{$\begin{array}{c}\text { \# of } \\
\text { Filaments }\end{array}$} & \multicolumn{2}{|c|}{ Tensile Strength } & \multicolumn{2}{|c|}{ Tensile Modulus } & \multirow{2}{*}{$\begin{array}{c}\text { Elongation } \\
(\%)\end{array}$} & $\begin{array}{c}\text { Approximate } \\
\text { Dry Fiber } \\
\text { Cost }(\$ / \mathrm{kg})\end{array}$ & $\begin{array}{c}\text { Cost per } \\
\text { Strength } \\
\text { metric }\end{array}$ \\
\hline High Performance & $12 \mathrm{~K}$ & 900 & $(\mathrm{MPa})$ & $(\mathrm{ksi})$ & $(\mathrm{GPa})$ & & \\
\hline Mid Performance & $18 \mathrm{~K}$ & 790 & 5,490 & 42.7 & 294 & 2.2 & $\$ 170$ & 6.8 \\
\hline Low Cost & $24 \mathrm{~K}$ & 711 & 4,900 & 33.4 & 230 & 2.1 & $\$ 20$ & 1.7 \\
\hline
\end{tabular}

Quantum evaluated four different carbon fibers from three different manufacturers. Figure 2 shows burst results for each of the materials. From these results it was determined that material 2 was the most cost effective of the fibers tested. 


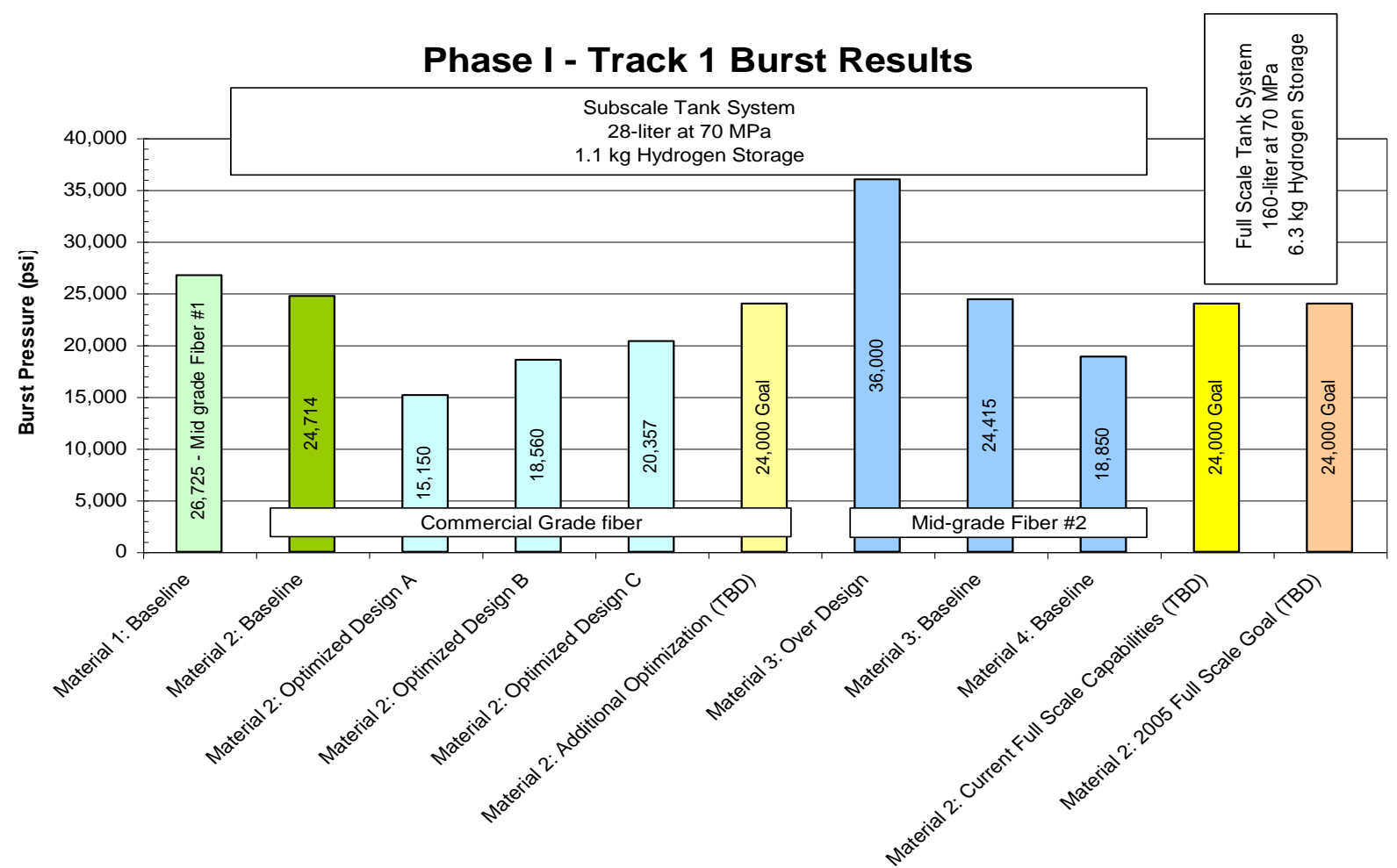

Figure 2 - Fiber Evaluation Burst Results

Further optimization of the layup and manufacturing process was conducted in order to reach a final material cost for the $28 \mathrm{~L}$ tank using low cost fiber of $\$ 1,300$. This tank was tested for burst and cycle performance and the results were compared to those of the baseline tank. Burst and fatigue data were not compromised and safety was considered to be equivalent to, or better than, the baseline design because of its greater composite wall thickness, which may give additional protection from exterior impact and abrasion. The gravimetric value did decline due to the increase of material used on the lower cost fiber. While the baseline tank has a gravimetric efficiency of $0.66 \mathrm{~kW}-\mathrm{hr} / \mathrm{kg}$, the low cost fiber tanks have a gravimetric efficiency of $0.83 \mathrm{~kW}-\mathrm{hr} / \mathrm{kg}$. When this was scaled up to the full scale tank at the end of the program, we were able to reach a gravimetric efficiency of $2.13 \mathrm{~kW}-\mathrm{hr} / \mathrm{kg}$. This was accomplished with only weight reductions in the tank and not in the BOP.

\subsection{Track 2 Objectives - Tank Instrumentation to Reduce Design Factor of Safety}

For track two, Quantum evaluated the use of "Active Sensing" in order to be able to reduce the design safety factor without compromising the safety of personnel around the fuel storage system. Quantum investigated the integration of strain sensors in the cylindrical and end domes of the composite structure. These integrated sensors would be linked to the vehicle electronics and could possibly shut down operation of the vehicle or prevent restart if readings indicated degradation of the tank had occurred (see Figure 3). 
Quantum Fuel Systems Technologies Worldwide, Inc

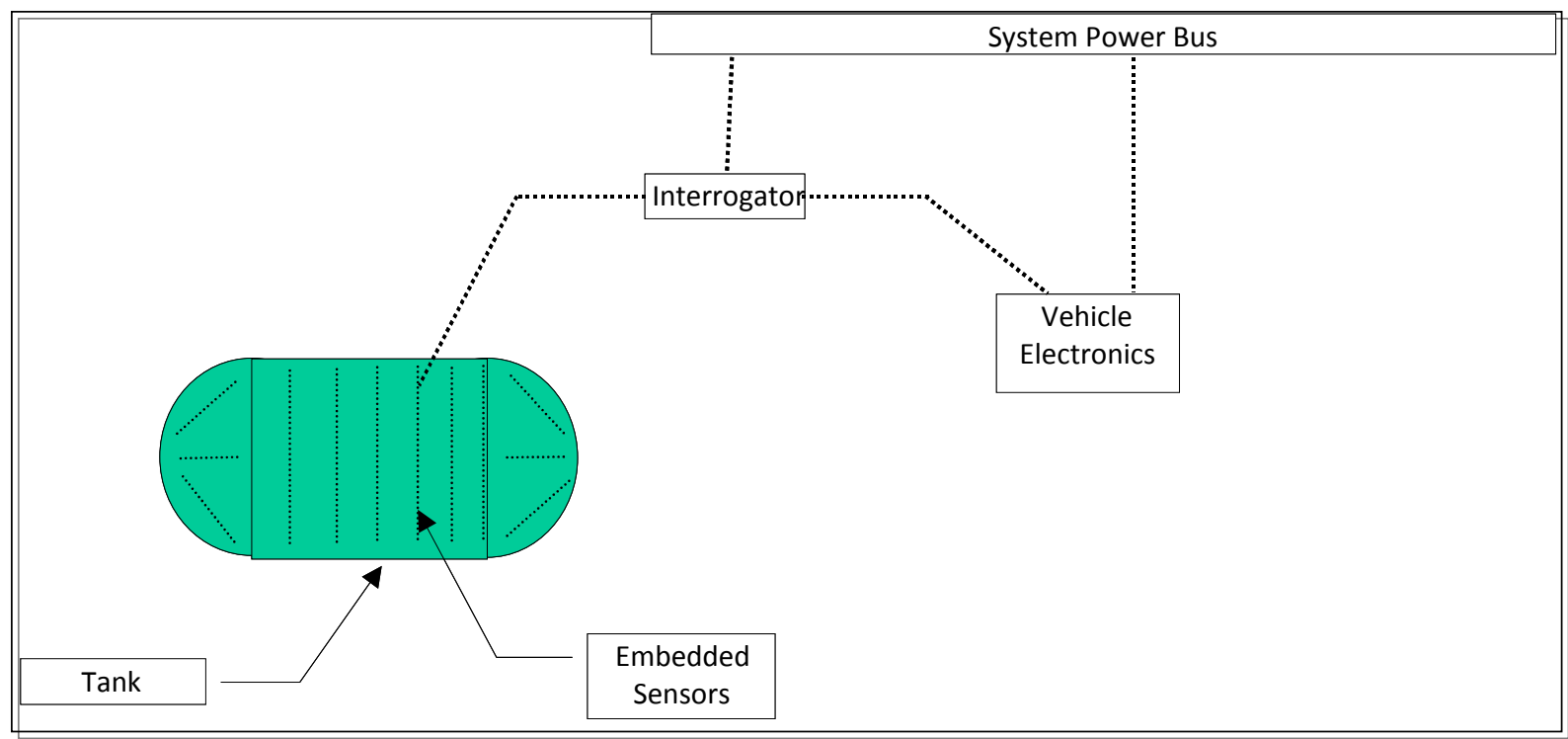

Figure 3 - Possible Vehicle Tank Monitoring Schematic

Quantum evaluated three different strain monitoring tools. These were biaxial strain gages, fiber optic cable, and "belly bands".

Initial evaluation was done by inducing localized damage on 10,000 psi tanks and monitoring strain change as the tank was cycled from 300 psi to $125 \%$ of service pressure. However, due to the rugged nature of the 10,000 psi tank, reproduction of the results was not achieved. For this reason evaluation was changed to a $34 \mathrm{~L}, 5,000$ psi tank.

Testing was conducted on the 5,000 psi tank design to determine sensor spacing requirements to ensure degradation of the composite structure prior to failure of the tank was captured. This was done by dropping the tank from 9 feet onto a steel bar. The Impact location was marked on the tank and strain gages were attached to the external surface along the longitudinal axis and around the circumference of the tank (see Figure 4). The tank was then pressure cycled and strains were monitored. The tank was pressure cycled at increasing pressures until strain levels were seen to be increasing. At 8,000 psi strains consistently increased until the tank failed 840 cycles later. Hoop (radial) strains near the impact location showed an increase in fiber loading; however, longitudinal strain decreased with each cycle as the helical layers carried less load. 


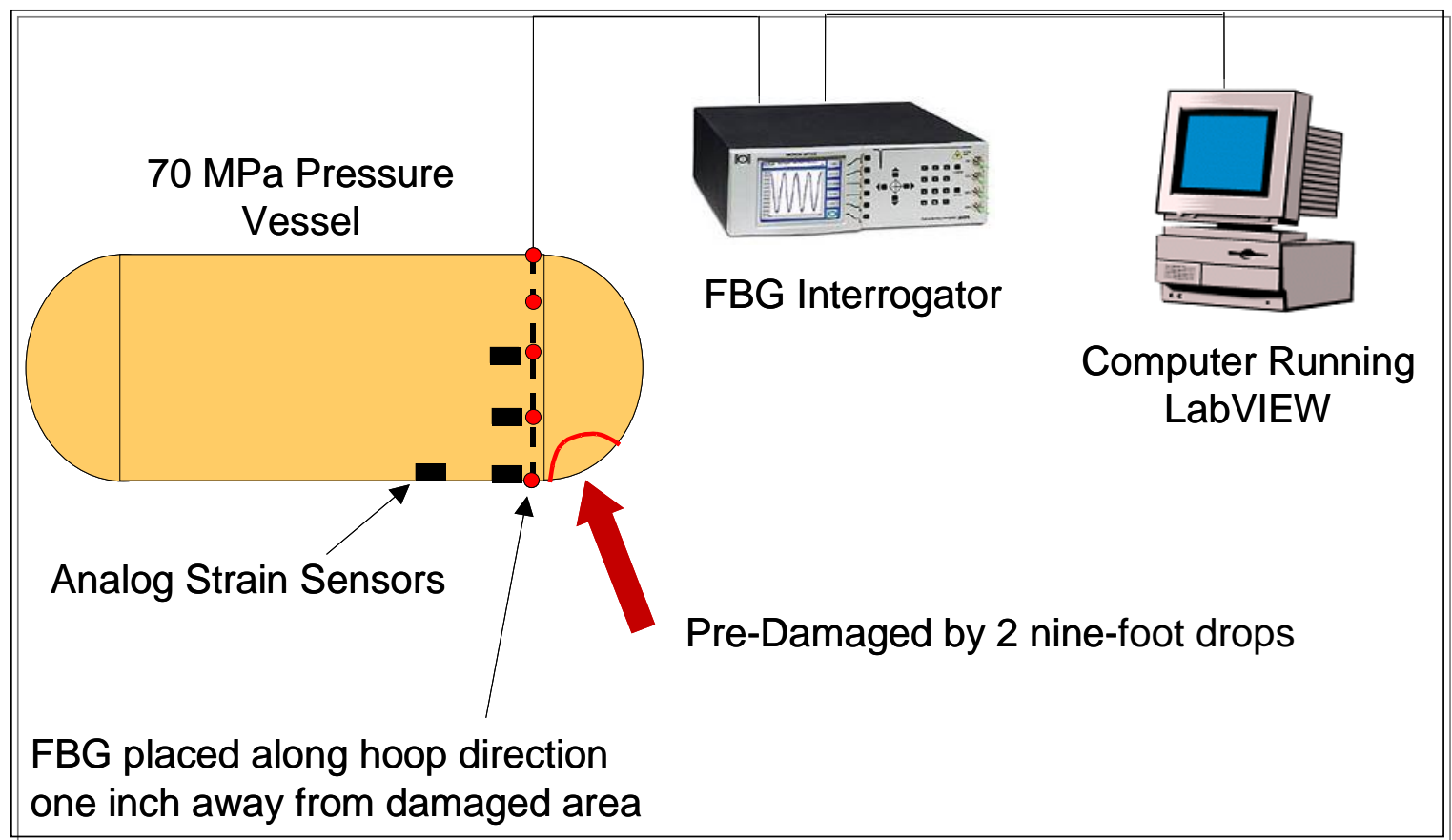

Figure 4 - Strain Gage and Fiber Optics Instrumentation.

These tests showed that the sensitivity range for the strain gages to detect the onset of tank degradation is in the range of one to three inches from damage location.

Next, Quantum investigated the use of fiber optic cables wound into the composite structure as a method to monitor the overall condition of the tank. Spacing of adjacent winds was based on the results of sensitivity tests conducted using surface mounted strain gages. Redundant fibers were wound into the tank to increase the odds of getting readings from the fiber optics. By sending light at a particular wave length and then monitoring the reflected signal, increases in length of the fiber optic can be measured. By calibrating the signal received from a FBG interrogator, we can get a strain reading from the fiber optic. This reading is then monitored to show the health of the tank.

Using the fiber optic cables to monitor tank health had mixed results. The system was able to monitor the entire tank and detect degradation of the composite structure; however the fiber optics were unreliable. Reliability issues were traced to the following areas:

- $\quad$ Damage to the fiber optic during winding

- Damage to the fiber optic where it penetrates composite

- Damage to fiber optic at connector

$>\quad$ Typically from connector weight causing optic to fold over

- Issues making a good connection for clear signal to FBG interrogator

When the instrumentation worked we were able to monitor degradation and demonstrated that damage that would lead to eventual failure of the composite structure could be detected several hundred cycles before the tank failed. Further work is required with the fiber optics in order to develop a more robust system.

The third method for monitoring increase in strain was using "Belly Bands". Belly bands are high resistance wiring that is wound around the tank. A constant low voltage is put through the wire and the 
DE-FC36-04G014010

Quantum Fuel Systems Technologies Worldwide, Inc

change of current is monitored as resistance of the wire fluctuates proportional to wire length and cross sectional area. Quantum did not commit significant effort on the "belly band" as signal quality was very poor and changes in strain as the tank deteriorated usually was less than the noise in the signal. This method could possibly be improved if sufficient isolation of the signal could be developed.

\subsection{Track 3 Objectives - Cool Fuel}

For Track three, Quantum looked at increasing the storage capacity of the compressed hydrogen tank by increasing the fuel density. Because the polymer liner is not able to withstand temperatures down to cryogenic levels, the temperature was limited to $203 \mathrm{~K}$. This allows a $23 \%$ increase in fuel storage over storage at ambient temperatures. Figure 5 below shows various strategies for the Cool Fuel System.

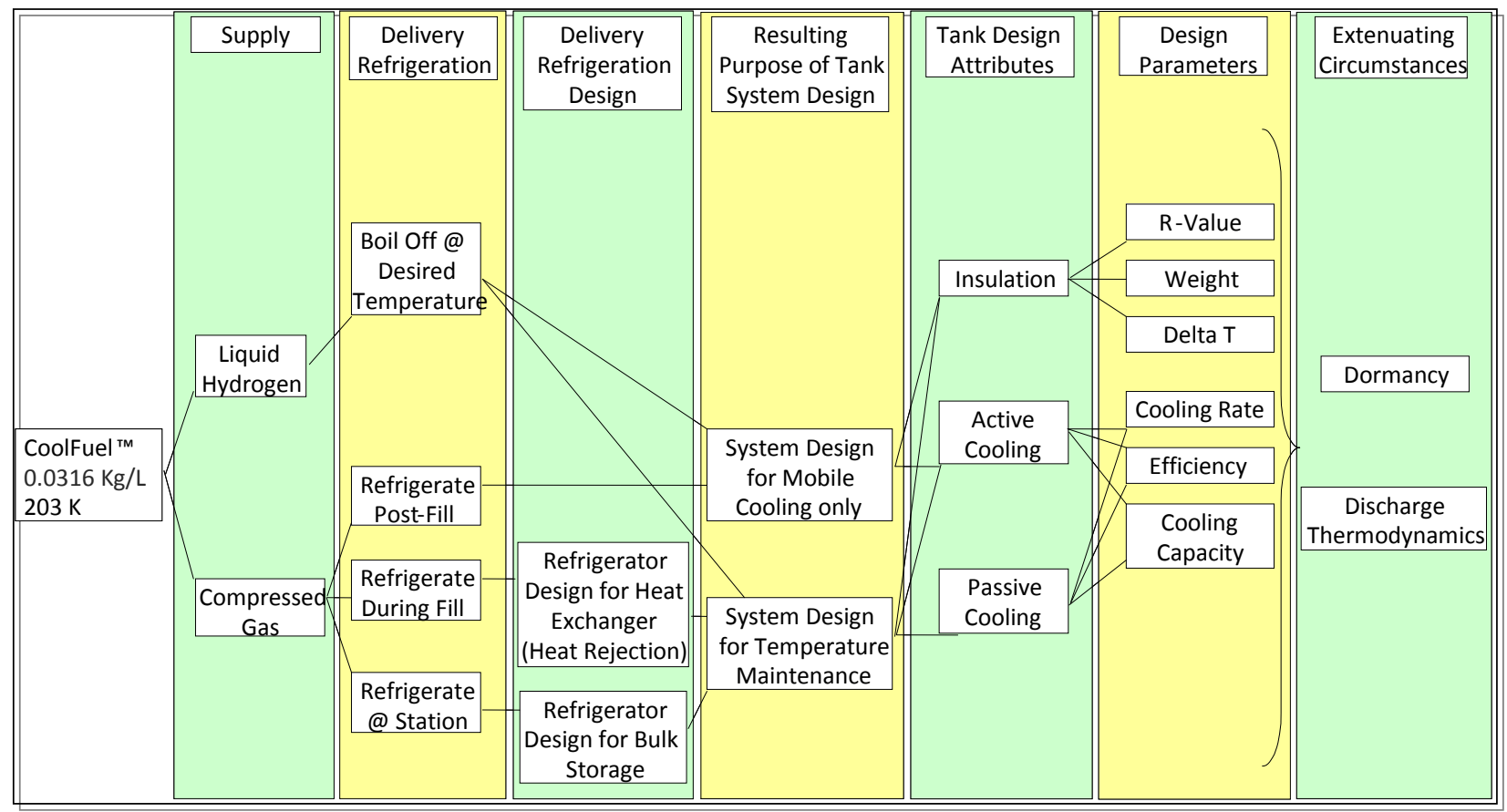

Figure 5 - Possible "Cool Fuel" Strategies

To evaluate which method to utilize Quantum built the following analytical models from first-principles. This work was subcontracted to FEA Technologies of San Clemente, CA.

\subsubsection{Thermodynamics}

The thermodynamics portion of the model included time-based solutions for the thermo physical properties of the fuel in the tank during the charging and discharging processes. The matrix of fuel properties was obtained from software that is commercially available from NIST. Isentropic, isothermal, and non-isothermal processes were modeled in order to bracket the parameters of interest. 
DE-FC36-04G014010

Quantum Fuel Systems Technologies Worldwide, Inc

\subsubsection{Thermal/Heat Transfer Modeling}

The thermal and heat transfer modeling were two-fold. First, a simple transient conduction and convection model was developed to simulate heat transfer from the gas internal to the tank to multilayered tank wall to gas around the tank. Second, a global or bulk model was developed to simulate heat transfer for the tank system as a whole and the heat impingement from the environment.

\subsubsection{Consumption Rate Phenomena}

Consumption rate phenomena have a strong bearing on the fuel temperature and pressure in the tank. Because the consumption rate problem adds considerable complexity to the time-based solutions, it received considerable attention.

For the full scale tank with a hydrogen density of $0.0316 \mathrm{~kg} / \mathrm{l}$ a $160 \mathrm{~L} 5,000$ psi tank would hold the required $5 \mathrm{~kg}$ of hydrogen. Based on the thermal analysis, achieving a gas temperature of $-70^{\circ} \mathrm{C}$ at the end of the fill is challenging due to heat of compression. This heat would have to be rejected during the fill at a rate of $8.3 \mathrm{~kW} / \mathrm{kg}$. Quantum proposed using a heat exchange system that would allow the filling station to remove this heat during the fill process (see Figure 6)

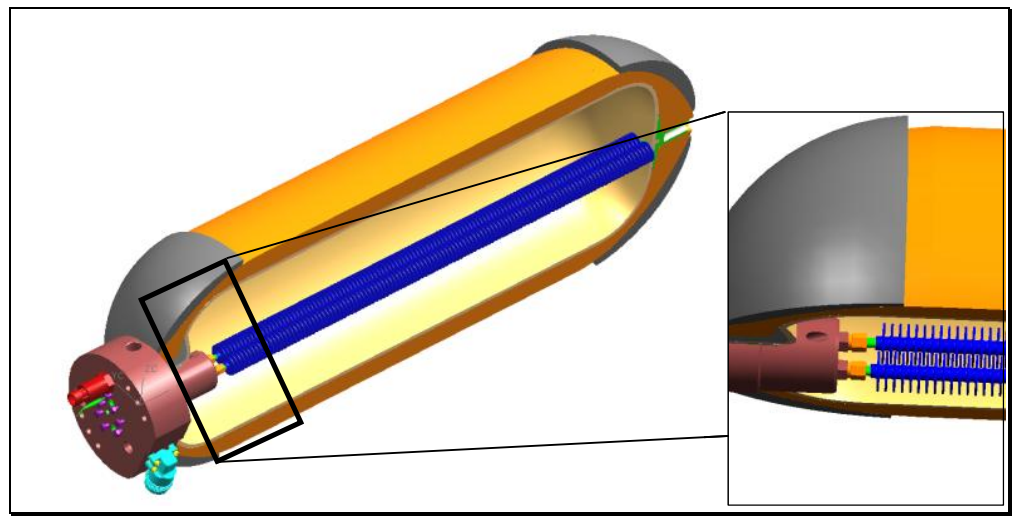

Figure 6 - Active Heat Rejection Concept

Calculations for maintaining fuel at $-70^{\circ} \mathrm{C}$ indicated that it would take significant energy to actively maintain low temperatures. For this reason Quantum investigated using insulation for maintaining temperatures in the tank. With adequate insulation, a tank can be left dormant for a period of approximately 10.5 hours before slow venting must begin (assumption: $22.5 \mathrm{~J} / \mathrm{s} / \mathrm{m}^{\wedge} 2$ of heat transfer, achieved with insulation providing $0.005 \mathrm{~W} / \mathrm{m}-\mathrm{K}$, or R30). Even if venting must occur to relieve all of the extra pressure, the worst-case result is a normal 5,000 psi system. Based on these results Quantum estimated that the most efficient strategy would be to design a system as shown in Figure 7. 


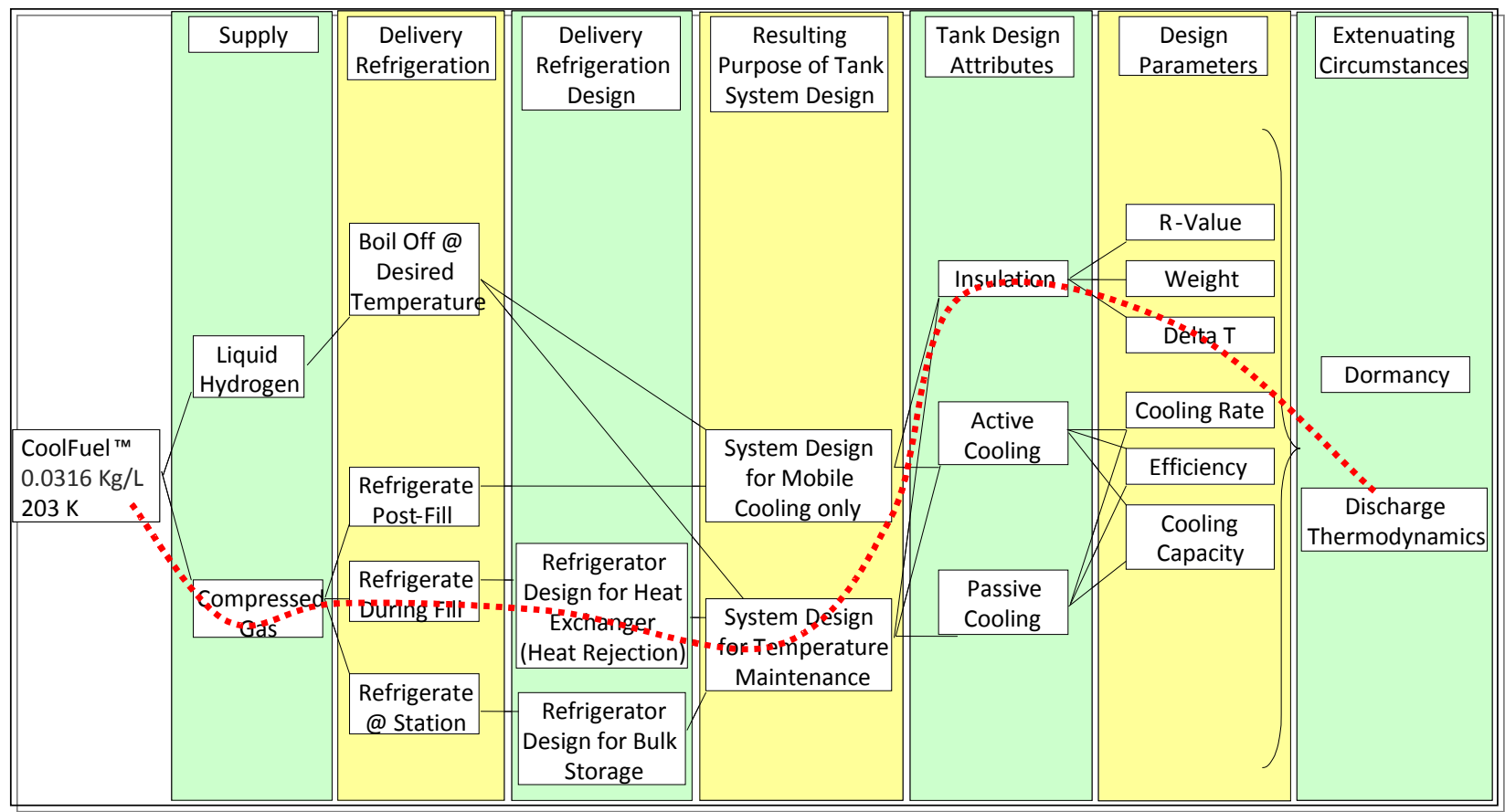

Figure 7 - Selected Strategy for “Cool Fuel” Design

A cost savings analysis for the "CoolFuel" based on estimates for increase in materials and equipment for insulating the tank and rejecting excess heat during refueling gave a net savings of less than $\$ 1 / \mathrm{kW}$ hr.

Based on the results of track 2 and track 3 yielding only small progress towards DOE Freedom Car goals activities on these two tasks were discontinued after 2006.

\section{Phase 2 Objectives}

Based on the results of the first three years of work, phase two efforts were focused on tank optimization of composite structure, polymer liner and metallic fittings.

\subsection{Track 1 Objectives - Composite Structure Optimization}

During phase one of the program, significant improvements were made in reducing pressure vessel cost by developing design and manufacturing techniques that allowed the use of "low cost" fiber. This, however, had a negative effect on volumetric and gravimetric performance as increased quantities of the low cost fiber were required as compared to the medium cost fibers.

In order to reduce carbon usage Quantum began looking for a way to continue the optimization of the composite structure using a technique called localized re-enforcement. This technique was thought to allow the composite to be better utilized for its strength capabilities. By better utilizing the strength of the composite, some of the composite would no longer be needed, allowing for weight reduction, decrease in the composite volume, and cost reduction of the pressure vessel. Quantum worked with Automation Dynamics of Albany, New York and ATK Space Systems of Ogden, Utah, both experienced advance fiber placement manufacturing facilities. With these outside vendors to assist with design, analysis and fabrication, three different tanks were developed. Unfortunately these tanks weighed more 
than the baseline tank and had lower performance in terms of burst strength. From the results of the development of the first advanced fiber placement tank, which was conducted over a one year period, it was decided that the scope of developing new hybrid filament wound and advanced fiber placement tanks was beyond the timing and budget for this program and that the remaining funds and time could better be spent on other areas of tank optimization. Continued research of advanced hybrid tanks is being conducted on a separate DOE co-funded program number DE-FG36-08G018055.

\subsection{Track 2 Objectives - Liner Optimization}

The goal of track two was to optimize weight, volume and cost of design and manufacturing technologies in liners. This was achieved through material development of the liner, specifically exploring characteristics related to PET and PEN plastics and other polymers. The aim of the study was to identify suitable materials that would meet the tank usage environment requirements and reduce the liner thickness. This in turn reduces tank cost and weight. In conjunction, a review of polymer molding options was evaluated.

\subsubsection{Literature Review}

The liner system can be made into either a single layer or multi-layer membrane. Besides acting as a barrier to prevent permeation of stored gas, the liner also serves as a mandrel for the filament winding process. The liner material is required to be of high toughness to eliminate the possibility of crack initiation stemming from an impact event.

HDPE is widely used as a liner material in type IV tanks because of its excellent toughness (especially at low temperatures), low gas permeability, and ease of manufacturing. Currently, the manufacturing process of HDPE liners is done by in-house rotational molding. The thickness of the liner averages $5 \mathrm{~mm}$, which is much thicker than commercial plastic bottles. This thickness is needed to meet the required low hydrogen permeation rate of less than $1.0 \mathrm{cc} /\left(I^{*} \mathrm{~h}\right)$ at service pressure and $20^{\circ} \mathrm{C}$.

The composite usage is proportional to the liner thickness. A thicker liner has a larger outside diameter for a set tank volume; therefore the composite has a larger inside diameter. At a given pressure the hoop forces on the inside of a composite structure are directly proportional to the diameter. The larger the composite inside diameter the higher the force on the inner-most composite layers ${ }^{1} . s$

To avoid failures of the composite inner-most layer, the composite wall thickness must be increased. However, increased composite wall thickness reduces the reinforcing efficiency of the composite material, because the stress distribution through the composite wall is not linear ${ }^{1}$. This in turn requires more composite usage to compensate for the non-linear loading of the composite. Cost and weight are therefore detrimentally affected by the increased usage of polymer (HDPE) material and composite. The aim then is to improve the cost and weight efficiency through a reduction in liner thickness, which requires the usage of materials with much lower gas permeability than HDPE, but with at least comparable toughness.

There are several considerations in evaluating potential polymer materials for the liner. As mentioned previously, the two most important ones are low gas permeability and high toughness (high impact resistance). There are also other considerations, depending on the application environment of the liner system, as well as the requirements the liner has to meet in order for the pressure vessel to pass standard tests [i.e. EIHP]. These include: 
DE-FC36-04G014010

Quantum Fuel Systems Technologies Worldwide, Inc

1. Thermal stability: the liner has to withstand an ambient epoxy curing temperature of about $150^{\circ} \mathrm{C}$ for at least 6 hours

2. Fatigue resistance to tensile and bending stress: the liner has to withstand at least 15,000 hydrostatic test pressure cycles, with the minimum pressure at $2 \mathrm{MPa}$ and maximum $87.5 \mathrm{MPa}$, and temperature between -40 to $85^{\circ} \mathrm{C}$.

3. The liner has to withstand chemical corrosion from automobile fluids. EIHP lists the following as reference: 19\% Sulphuric acid solution, 25\% Sodium Hydroxide solution, 5/95 Methanol/Gasoline, 28\% Ammonium Nitrate solution, and Windshield washer fluid.

4. Lastly, the raw material cost is an important factor to consider.

As a review, gas permeability measures the ease with which a gas can pass through a medium (polymer liner in this case). Gas permeability therefore is a function of the plastic material in terms of molecular interaction, crystalline, molecule orientation, filler content, cross-linking density and fluorination. Since there is limited information on hydrogen gas permeability in plastic materials available, we use the permeability data to other gases as reference for comparison reasons, such as $\mathrm{CO}_{2}, \mathrm{H}_{2} \mathrm{O}, \mathrm{N}_{2}$, etc.

Initially, we studied existing materials which are used in bottle and packaging applications and have excellent barrier performance to gases. A literature review was done to understand material limitations and provide a basis to commence development work. Some examples of these materials are listed and compared in Table 1, courtesy of Flextank Inc. ${ }^{2}$

Table 1. Gas Permeability of various polymers at $80 \%$ R. H.

\begin{tabular}{|c|c|c|c|c|c|c|}
\hline \multirow{3}{*}{ Polymer } & \multicolumn{6}{|c|}{ Permeability, cm3/m2/24 Hrs, atm/1 mm } \\
\hline & \multicolumn{2}{|c|}{ Oxygen } & \multicolumn{2}{|c|}{ Carbon Dioxide } & \multicolumn{2}{|c|}{ Nitrogen } \\
\hline & $25 \circ \mathrm{C}$ & $35 \circ \mathrm{C}$ & $25 \circ \mathrm{C}$ & $35 \circ \mathrm{C}$ & $25 \div \mathrm{C}$ & $35 \circ \mathrm{C}$ \\
\hline EVOH, (i.e. "EVAL F”) & 0.021 & 0.051 & 0.075 & 0.16 & 0.002 & 0.005 \\
\hline PVDC, (i.e., "Saran") & 0.058 & 0.17 & 0.43 & & 0.05 & \\
\hline Oriented Nylon 6, (i.e., Cryovac) & 0.64 & 1.3 & 2.6 & & 0.27 & \\
\hline $\begin{array}{l}\text { Unoriented Nylon } \\
\text { pouch) }\end{array}$ (food/dairy & 1.6 & 3.1 & & & & \\
\hline Oriented PET (i.e., bottle grade) & 0.90 & 2.0 & 7.6 & & 0.18 & \\
\hline Unoriented PET (un-metallized) & 1.8 & 4.0 & 15 & & & \\
\hline Metallized PET (25-50 $\mu$ for wine) & $\sim 2.0$ & & & & & \\
\hline HDPE (S. G. $=0.96)$ & 58 & 111 & & & & \\
\hline HDPE (S. G. = 0.935) & 117 & 190 & & & & \\
\hline LDPE (S. G. = 0.92) & 215 & 289 & & & & \\
\hline HIPS & 101 & & & & & \\
\hline Unoriented PVC & 6.5 & & & & & \\
\hline
\end{tabular}

The most promising material for further study is poly ethylene terephthalate (PET), used extensively in packaging applications because of its gas barrier performance and optical clarity when compared to PE. It is also comparable in price ${ }^{3}$. The gas permeability of PET can be further reduced by laminating or blending it with some low permeability material like liquid crystalline polymers (LCP). This however 
requires very good adhesion between the two components and has a lot of challenges in the blending process because LCP needs to form a continuous phase to effectively reduce permeability. Some success has been realized with a PET/LCP blend whereby 30 wt\% LCP exhibited $96 \%$ lower oxygen permeability than raw $\mathrm{PET}$.

It was found that poly ethylene naphthalate (PEN), saran, EVA or acrylonitrile copolymers ${ }^{4}$ can be used as a barrier, and coextruded with PET to form a tube structure, which can be cut into desired length and blown into certain articles. However, these barrier materials do not adhere to PET well and delamination could happen. Some barrier materials like copolymers of terephthalic acid and isophthalic acid with ethylene glycol have similar chemical structures as PET, and, therefore, they possess good miscibility. These barrier materials can form blends with PET to lower the PET gas permeability without serious delamination ${ }^{5}$. Nano clay reinforced PET formulations were also developed because they have improved gas barrier properties ${ }^{6,7,8}$. It was found that organic modification of montmorillonite clay to exchange $\mathrm{Na}+$ with an amino acid salt increases the spacing between silicate layers and makes the galleries between the layers more organophilic (water resisting) ${ }^{7,8}$. The addition of the product to PET modified by $-\mathrm{SO}_{3} \mathrm{Na}$ results in highly exfoliated nanocomposites by a simple extrusion process. In the molding process, it is a common practice to stretch the polyester 2.5 times or more to fully orientate the molecular chains in order to reduce the gas permeability and improve the impact resistance ${ }^{9,10}$. Another common practice to improve the barrier performance is to coat it with a low-permeability barrier layer $^{11}$. The barrier material can be poly vinyl alcohol ${ }^{12,13,14,}$ EVA, copolymer of ethylene and vinyl alcohol14, PVC, poly vinyl chloride ${ }^{12}$ PVDC, poly vinylidene chloride ${ }^{15,16}$, polyamine-polyepoxides ${ }^{17}$, etc.

Similar to coating, multi-layered structures were also created based on PET, with copolyester used to affect the adherence between PET and the barrier material ${ }^{18,19}$. The multi-layered structures are usually made by extrusion, blow molding, or injection molding wherein each layer is allowed to cool before the next layer is injected. During the molding operation, PET gas permeability can be reduced significantly by effective stretching ${ }^{20}$. It was found that during orientation, the PET chain becomes aligned, and aromatic rings and crystal planes are thought to become parallel with the film surface. Stretching in the 2nd direction redistributes the structure, and forms a new balanced structure with the PET aromatic rings and crystal planes almost parallel to the film plane, which further improves the barrier performance.

Polyethylene naphthalate (PEN) is a polyester with excellent barrier properties (even better than PET because of its low chain flexibility) $)^{3,20,21,22}$. It is prepared from ethylene glycol and one or more naphthalene dicarboxylic acids by condensation polymerization. Because it provides a very good oxygen barrier, it is particularly well-suited for bottling beverages that are susceptible to oxidation, such as beer. Because of its superior mechanical properties, it is also used for manufacturing high performance fibers that have very high modulus and better dimensional stability than Polyester or Nylon fibers. The disadvantage of PEN versus PET is in its price.

But, the advantage is clear regarding PEN; the wall thickness will be thinner than PET, which means less material is used, thereby closing the cost gap. Using drawing and stretching processes will lead to molecule reorientation, closer chain packing, crystallization, and thereby reduced molecular mobility. Substantial improvement in gas barrier properties are gained because the non-permeable crystalline regions are perfected and the ordering effects are imparted to the amorphous regions. The problem in drawing/stretching PEN is necking ${ }^{20}$, and high draw areas have to be employed to produce films of uniform thickness. This is because of the highly localized and rapid alignment of naphthalene planes parallel to the film surface above its transition glass temperature ${ }^{22}$. Blending PEN with PEI helps to reduce the necking effect. Necking disappears at 10\% PEI in PEN/PEI blends. X-Ray studies show that PEI 
hinders the rapid alignment of naphthalene planes. PEI chains were also thought to increase the overall friction between PEN polymer chains because PEI is completely miscible with PEN.

Nylon is a high-performance polymer material with outstanding mechanical properties and chemical resistance. Compared to HDPE, nylons constitute an alternative in applications where elevated temperatures, aggressive media, contaminated soils and reduced gas permeability are present or required. Among nylons, Nylon 12 and Nylon 6 have been studied the most due to their use in packaging applications. Nylon 12 piping possesses significantly higher resistance to internal pressure, even at higher temperature levels, and considerably lower gas permeability then HDPE. Nylon 12 has been used as piping material for low-pressure supply articles (about 4 bar $=0.4 \mathrm{MPa}$ ) in Australia, Poland and Chile for over 10 years ${ }^{23}$.

Many research studies have also been done on Nylon 6, usually blended with Nanoclays to improve the barrier properties ${ }^{24,25,26}$. Once the exfoliated clay structure is formed inside Nylon 6, it acts as an effective gas barrier. In the reference study 24 , the Nitrogen gas permeability dropped by more than $90 \%$ compared to raw Nylon 6, when it was blended with $15 \%$ by weight of Ultrafine Full-Vulcanized Powdered Rubber/Clay Montmorillonite. The main concern with nylon materials is the relatively low impact strength, especially at low temperatures, compared to $\mathrm{HDPE}^{27}$. Therefore, when used as package materials, quite often nylon is blended with some lower-permeability and more-flexible materials to improve the clarity, flexibility and toughness. Some blends of Nylon/PET were developed which have even lower permeability ${ }^{28}$.

Furthermore, much work is still required to develop multi-layered structures ${ }^{29,30,31,32,33,34,35,36}$ because generally it is difficult to find a single component material which is capable of providing the correct balance of all the properties that are required for various types of packaging applications ${ }^{37}$. For example, polyolefins like HDPE have excellent toughness but suffer from poor gas barrier properties. High nitrile polymers or EVOH have outstanding gas barrier properties but have only modest moisture resistance. Quite commonly the multi-layer structure includes thermoplastic material such as HDPE, PET, etc. on the outside and a gas barrier such as EVOH, PVDC, Poly Acrylonitrile (PAN) ${ }^{37}$, etc. in the middle, protected from environmental damage like moisture and mechanical damage. Because most polymers are not quite miscible, a tie layer has to be used to bond the thermoplastic layer and barrier layer together. Usually the molded articles take the form of preforms and the containers are blow molded therefrom and the barrier layer is subsequently applied ${ }^{32,36}$. The articles can also be made by compression molding, co-extrusion, or lamination ${ }^{37}$. The disadvantages of the multi-layered structures are their relatively higher cost, more complicated manufacturing process, and possible delamination under pressure cycle environment in Type IV tanks.

One interesting topic that came up during the literature review regarding multi-layer structures is packaging materials that comprise of a polymeric base component and a thin barrier component which coats and lines a surface of the base component ${ }^{38,39,40,41,42,43,44,45,46,47,48,49,50}$. The base surface is usually subjected to a reactive gas environment containing $\mathrm{F} 2, \mathrm{Cl} 2, \mathrm{O} 2, \mathrm{O} 3, \mathrm{SO} 3$, oxidative acids, or mixtures, etc. at a temperature and gas partial pressure to increase the base material surface energy above 40 dynes/cm, to offer adhesion of the barrier coating, and then the barrier coating is applied ${ }^{41}$. Such a technique is reported to have reduced the permeability of the base material significantly ${ }^{46}$ while maintaining excellent toughness ${ }^{41}$. The coating can also be a polymer with very low permeability, directly polymerized on the base thermoplastic material surface ${ }^{47}$ or it can be fluorinated ${ }^{51}$. 
Additional coatings are melamine-formaldehyde or urea-formaldehyde condensation products ${ }^{52}$, epoxy resins $^{53,54}$, copolymers of vinylidene dichloride ${ }^{55}$, etc. Usually, the coating is applied after the article is made, but information in several patents [items 48 to 50 in the endnotes] described a process in which the barrier material is coated to the plastic surface when the PET is still a preform, and then the part is blow-molded into the final article. Because this technology can be used to improve the barrier performance of HDPE, we would consider pursuing this in our current rotational molded HDPE liners. The difficulty may be that HDPE generally has poor adhesion with other materials, and the coating may lower its impact strength.

The last category of barrier materials that was studied is fluorinated HDPE. Compared to the base HDPE, fluorinated HDPE has much better chemical resistance, flame resistance, thermal stability, and gas barrier performance. However, it is more expensive on a per pound basis and weighs much more than HDPE. For example, HDPE has a density about $0.9 \mathrm{~g} / \mathrm{cc}$, and Tefzel [ethylene-tetrafluoroethylene copolymer], a Dupont material, has a density of $1.71 \mathrm{~g} / \mathrm{cc}$. Therefore, if fluorinated HDPE is used to replace HDPE, it doesn't necessarily mean we can reduce the liner cost and weight. Nevertheless, because the cost driver is the composite, any reduction in the liner thickness will affect the composite usage, which will directly affect system cost and weight ${ }^{56}$.

The team considered PET, PEN, nylon, multi-layer structures, fluorinated HDPE, and HDPE coatings from a material permeability [gas barrier performance] perspective in our liner development work. Due to the importance of liner application requirements, such as toughness, cycle fatigue life, torsional strength, etc., we concurrently evaluated these different properties in our development work. A number of polyester and polyamide resins were evaluated and tested for their mechanical, thermal, and permeation properties in order to achieve the desired permeation rate of the system.

Three basic molding processes can be used to make the liner structures: blow molding, injection molding, and rotational molding. Currently Quantum rotationally molds the HDPE cylindrical liners inhouse. Rotational molding naturally becomes the first choice for Quantum to evaluate any potential liner materials. Compared to other molding technologies, rotational molding is more ideal for manufacturing hollow shapes in a variety of sizes, which results in better part wall thickness distribution. However, rotational molding requires that the materials used have good flow-ability, i.e., very low viscosity at zero-shear-rate, therefore a lot of materials with very good barrier properties cannot be used due to relatively high viscosity, like PET or PEN. For this reason, we worked with injection molding and blow molding vendors to perform liner development. Rotational molding has other deficiencies, including that the raw material has to be grinded into a fine powder to help the material flow freely, which causes additional cost. Moreover, the cycle time is comparably long and therefore is not a good choice for high-volume production. Currently, the cycle time to make a HDPE liner is in the magnitude of an hour, whereas in blow molding 1000 cylindrical shaped bottles can be manufactured per minute.

To address one of the most important objectives of this project, the reduction of the system cost, we experimented with blow molding to significantly reduce the cycle time from the current hour to a few seconds. Furthermore, we would be able to improve on some characteristics of rotational molding. In rotational molding, the polymer material has a low shear rate which does not allow the macromolecules to be fully oriented to reach the desired performance characteristics, such as permeability.

If the liner material can be fully oriented during the molding operation, as it can be in blow molding (especially stretched blow molding) and injection molding processes, and if the barrier performance is improved significantly, then we not only reduce the material cost by being able to use a thinner liner 
DE-FC36-04G014010

Quantum Fuel Systems Technologies Worldwide, Inc

and less composite materials, but also reduce the system weight, which was another important goal for this DOE project. For these reasons we considered blow molding, especially stretched blow molding and injection molding.

\subsubsection{Prototype Liner Development}

In summary, the following are desired properties for liner materials:

1. Low hydrogen gas permeability

2. High toughness

3. Good thermal stability

4. Fatigue resistance to tensile and bending stress

5. Moderate tensile strength during winding [0.1 0.3 MPa]

6. Chemical corrosion resistance to: $19 \%$ Sulphuric acid solution, $25 \%$ Sodium Hydroxide solution, 5/95 Methanol/Gasoline, 28\% Ammonium Nitrate solution, and Windshield washer fluid

7. Low cost, density and CTE (coefficient of thermal expansion); easy process-ability

Using these requirements as a guideline, we proceeded to evaluate the suitability of the following materials for hydrogen storage vessels: HDPE, PET, PEN, Nylon, Multi-layered polymer structure. We also tested fluorinated HDPE to find any potential barrier properties advantages. We contacted material vendors to explain our application and to gain a better understanding of processing/manufacturing issues as well as learn from their experiences with these materials. Simultaneously, we made contact with vendors with blow molding development expertise to aid us in developing small scale bottles using both stretched blow molding and extrusion blow molding to meet the DOE cost ad weight targets.

To evaluate the suitability of blow-molding, Quantum leveraged the expertise of vendors to model, blow mold and test samples. One item we relied on these experts for was to understand the existence of any constraints for the preferred liner profile. In pressure vessels made of fiber reinforced composites, the orientation of the reinforcing fiber is determined through stress analysis. And in continuous filament winding, it requires a special liner surface profile such as the principle radius of curvature in both meridian and parallel directions, and coefficient of friction to lay the fiber in any preferred orientation.

\subsubsection{PET liner development: Injection stretch blow molding (ISBM)}

One of the most promising materials for our application is PET. We chose to work with vendor A due to their extensive experience in stretch blow molding development of PET. As a reminder, ISBM requires that a preform is made through injection molding, and then the preform is stretch blow molded into the final shape. As part of the scope of the program, we decided to only do small scale manufacturing development due to the high cost of tooling for our current sized liners using injection molding or blow molding. The test samples are based on a 1-liter liner in order to prove the concept. Three separate phases were agreed on; modeling, manufacturing and testing.

The development work commenced with modeling work to ensure feasibility based on wall thickness. The performance model was designed to predict the hydrogen gas permeation based on the material permeability to hydrogen gas, material thickness, stretch ratio, and container geometry (from 3D CAD structure model), as well as to container closure, coatings, filling condition and storage conditions. These inputs aided in predicting best scenario cases for the following phase in this project. Several modeling iterations produced the 'ideal' 1-liter liner model that meets the allowed hydrogen gas 
DE-FC36-04G014010

Quantum Fuel Systems Technologies Worldwide, Inc

permeation rate in EIHP. The model produced the material (PET) formulation, the required stretch ratio, and material usage (thickness). The latter item is the most critical to the overall project since the aim is to reduce material usage and consequently lower cost and weight. A dimensioned illustration of this liner is shown in Figure 1 below.

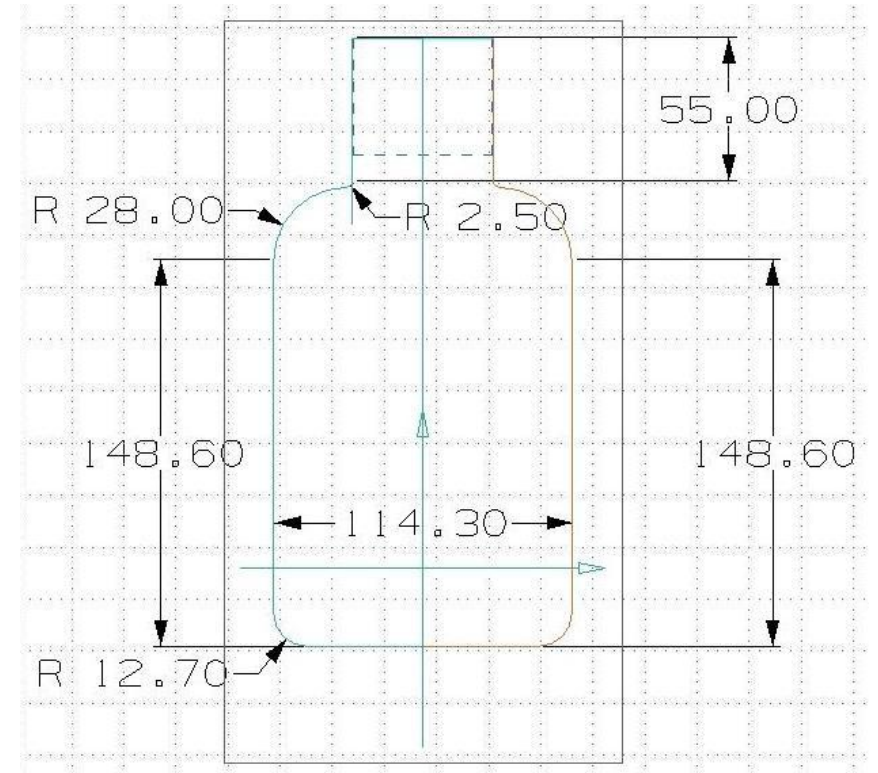

Figure 8 - Initial Design of 1-liter PET liner; dimensions in $\mathbf{m m}$

The second phase of vendor A's work is the injection-blow molding development work. The preform was manufactured according to the CAD model determined in the first phase and the required stretch ratio. Feasibility of manufacturing such a container proved successful and several parts were made to test in Phase 3.

During this last phase, the 1-liter container's performance was evaluated. The tests included pressure cycle fatigue life, drop-impact damage tolerance and hydrogen gas permeation level. Since the technology of our application is outside the current PET knowledge, the liner performance did not meet goals on the first iteration. Therefore, a few iterations in design and molding process development were implemented.

\subsubsection{PEN liner development: Injection stretch blow molding (ISBM)}

Another promising material/process combination is PEN blow molding development. Since PEN has inherently lower gas permeability than PET and HDPE, it requires less thickness for the same hydrogen gas permeation level compared to the aforementioned materials. The aim again here was to use less material, which in turn allows us to use less composite as explained earlier.

We partnered with vendor B because of their extensive expertise in developing blow molded PEN containers, especially for high pressure applications. In this project we decided to use existing containers that met some pre-determined parameters to do performance testing. These 4-liter high pressure vessels were adapted at Quantum to better reflect the geometry of our liners. The bottle is shown in Figure 9. There is a possibility that filament winding development may occur on this 4-liter container without valve. 


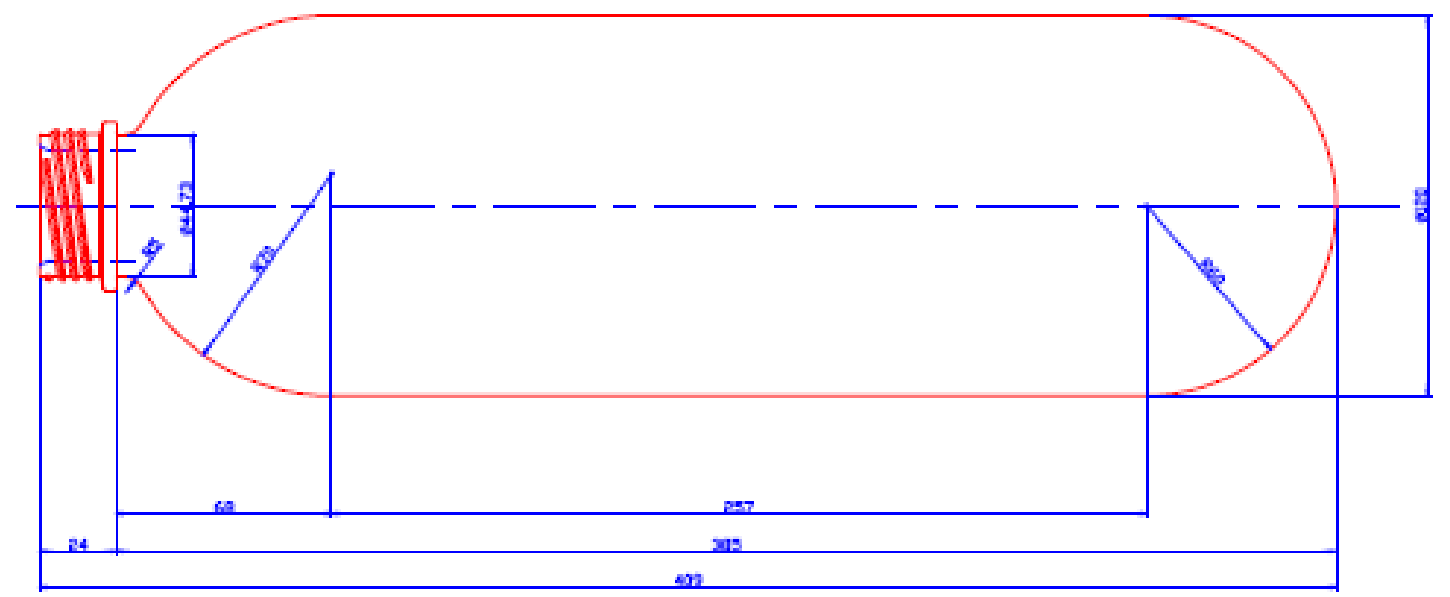

Figure 9 - Geometry of the 4-liter PEN bottle

In order to test the performance of the 4-liter liner, a high pressure cylinder made of steel was purchased, with inner dimension approximately $620 \mathrm{~mm}$ length and $140 \mathrm{~mm}$ diameter. The 4-liter liner is situated in the center of the pressure cylinder with epoxy resin filling the rest of the cylinder. A high pressure fitting, shown in Figure 10 below, was designed according to the opening size of the liner, so that it can be filled with high pressure hydraulic oil. The fitting has a groove for an o-ring which seals the fitting and the inner surface of the liner.

The aim of this set-up was to pressure cycle the 4-liter liner to test its fatigue resistance, while the steel pressure cylinder withstands the stresses due to high pressures. In addition, an enclosure shown in Figure 10 below was designed, so that the 4-liter liner can be fully enclosed without the fear of any leakage. This was done to be able to drop-test the container assembly from a certain height at low temperature to evaluate its damage tolerance.

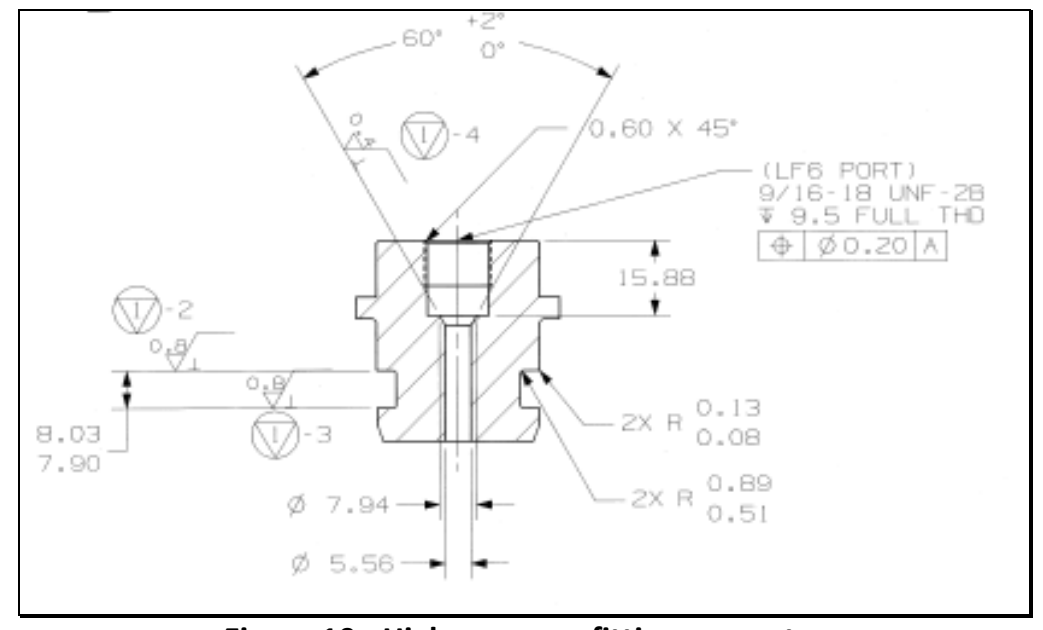

Figure 10 - High-pressure fitting geometry

Carbon fiber composite was wrapped around the threaded neck region of the 4-liter liner, in order to increase its stiffness, or resistance to radial expansion, which happens under pressure cycling and may result in a loss of seal. Images describing the set-up are shown in Figure 11 below. 
Concurrently, a hydrogen gas permeability measurement test was made on flat sheets of PEN with different thickness but similar stretch condition as that in the 4-liter bottle.

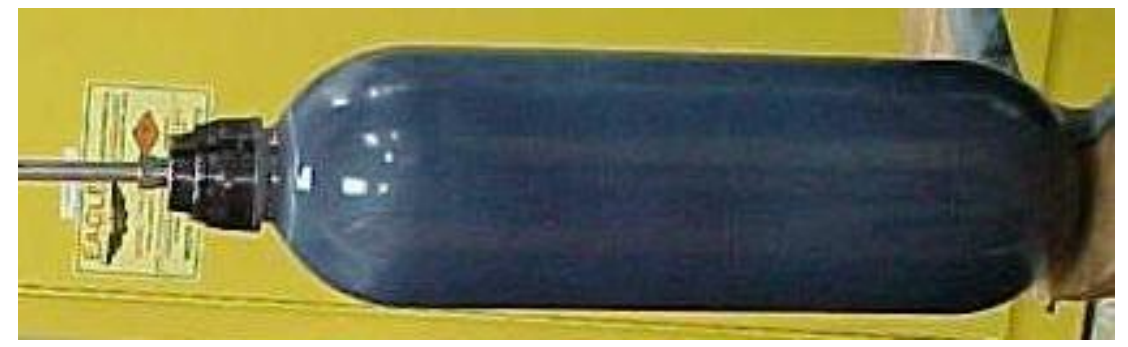

(a). PEN Bottle filled with Hydraulic fluid

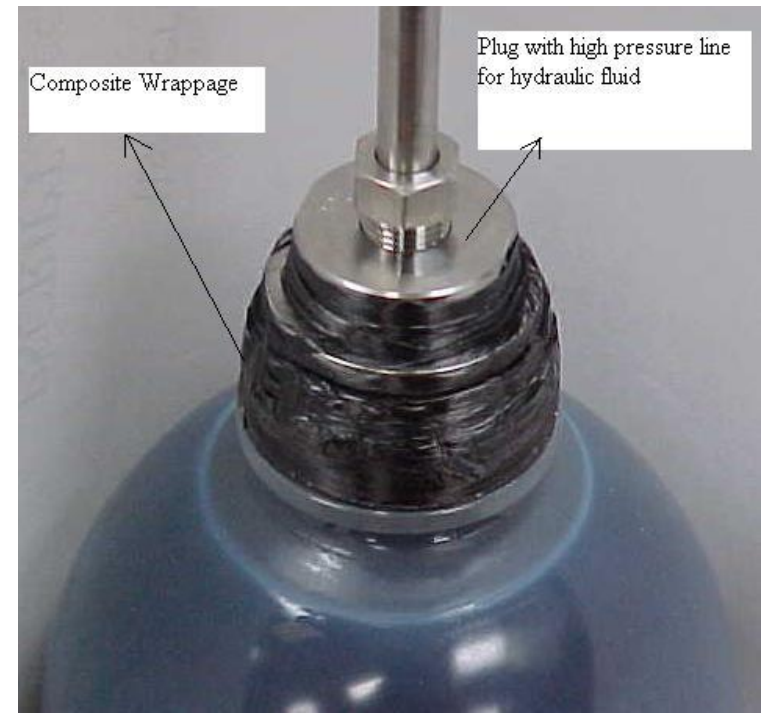

(b). Close-up view of the liner neck

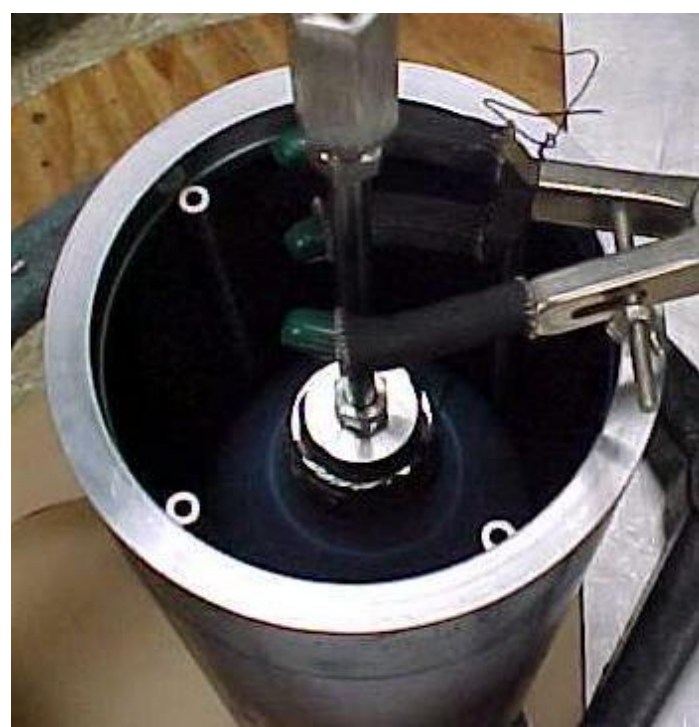

(c). PEN liner centered in the test cylinder

Figure 11 - PEN liner pressure cycle test experimental set-up

\subsubsection{HDPE Development: Extrusion blow molding (EBM)}

A great advantage of EBM over ISBM is that it can be used to make liners much larger and at a much lower tooling cost than ISBM. EBM currently is able to produce liners comparable in size to what Quantum makes from rotational molding, typically 30 liter to 900 liter. This technique is quite common. Naturally, this manufacturing technique is desirable for large-scale production since not only does one benefit from the aforementioned material development cost savings, but also from the dramatic cost savings from an increase in production as well as from a reduction in processing labor. Tooling costs would be negligible at the DOE assumed volume of $500 \mathrm{~K}$ parts per annum.

A set of 18-liter EBM molded HDPE bottles were acquired for developmental testing. Tensile test and Izod impact test coupons were sampled in an axial direction from different bottle locations.

The dimension of the tensile test specimen was determined according to ASTM D 638, and the test speed was $50 \mathrm{~mm} / \mathrm{min}$ (ASTM specification), and $500 \mathrm{~mm} / \mathrm{min}$ which is closer to the liner strain rate in the vessel pressure cycle test. The Izod impact test specimen dimension was determined according to 
DE-FC36-04G014010

Quantum Fuel Systems Technologies Worldwide, Inc

ASTM D256. The resultant data was compared with data gathered from HDPE liners produced using our conventional rotational molding. Table 2 summarizes the two sets of data.

Table 2 - Tensile and Izod test comparison between EBM and rotational molded specimens

\begin{tabular}{|l|c|c|c|c|c|}
\hline & \multicolumn{2}{|c|}{$50 \mathrm{~mm} / \mathrm{min}$ Speed Tensile test } & \multicolumn{2}{c|}{$500 \mathrm{~mm} / \mathrm{min}$ Speed tensile test } & Impact test \\
\hline & Modulus, MPa & Strain at Yield, \% & Modulus, MPa & Strain at Yield, \% & $\mathrm{J} / \mathrm{m}$ \\
\hline EBM & $1124.37 \pm 25.17$ & $8.46 \pm 0.32$ & $1262.31 \pm 35.54$ & $6.79 \pm 0.27$ & $115.11 \pm 2.35$ \\
\hline $\begin{array}{l}\text { Rotational } \\
\text { molding }\end{array}$ & $850 \sim 950$ & $10.25 \sim 11.65$ & $945 \sim 1020$ & $9.25 \sim 9.95$ & $\begin{array}{c}\text { Non-break, }> \\
600\end{array}$ \\
\hline
\end{tabular}

The results demonstrate that EBM produces more brittle liners than rotational molding. The reason for this is because EBM has a stretching effect on the HDPE macromolecules while such orientation in rotational molding is almost non-existent. The orientation increased the modulus, made the liner more brittle and more than likely will decrease permeability. Since toughness is one of the most important liner properties, we determined not to pursue this manufacturing/material combination any further.

\subsubsection{Multi-layered structure development: Extrusion blow molding (EBM)}

Multi-layered structures are commonly used in applications where excellent barrier properties are required such as in gasoline tanks. These structures commonly use thermoplastic materials such as HDPE, PET, etc. on the outside and a gas barrier such as EVOH, PVDC, Poly Acrylonitrile (PAN), etc. in the center, protected from environmental damage like moisture and mechanical damage. Because most polymers are not quite miscible, a tie layer has to be used to bond the thermoplastic layer and barrier layer together. The disadvantages of the multi-layered structures are relatively higher cost, a more complicated manufacturing process, and possible delamination under pressure cycle environments (very common with Type IV tanks, especially under temperature cycling).

The regrind layer in the multilayer process is reprocessed material that is run through a separate extruder and does not serve to protect anything, but exists simply to reduce processing scrap. These multilayer structures are blow molded, with each layer extruded separately and introduced into the machine head at different stages to create the layered structure. The layers are then extruded through a die to form a hollow tube that is blown into the cavity to form the final shape.

We acquired several 6-layer flat panels cut from different gasoline tanks to ensure statistical independence from each other. Figure 12 illustrates a multi-layer structure comprised of HDPE, Regrind, Adhesive, EVOH gas barrier, Adhesive, and HDPE.

As seen from Figure 12, most of the material in the construction is HDPE, which has an average coefficient of thermal expansion (CTE) of $0.00012 \mathrm{~cm} / \mathrm{cm} /{ }^{\circ} \mathrm{C}$, which is different from that of the Adhesive layer and EVOH layer. Due to the mismatch of CTE, thermal cycling caused by pressure cycling may be a problem. Interlaminar stress induced by pressure cycling may also cause delamination. Due to these predictable problems, tensile test coupons were made according to ASTM D638 from the aforementioned flat panels. Tensile testing at $50 \mathrm{~mm} / \mathrm{min}$ and $500 \mathrm{~mm} / \mathrm{min}$ speeds was evaluated. 


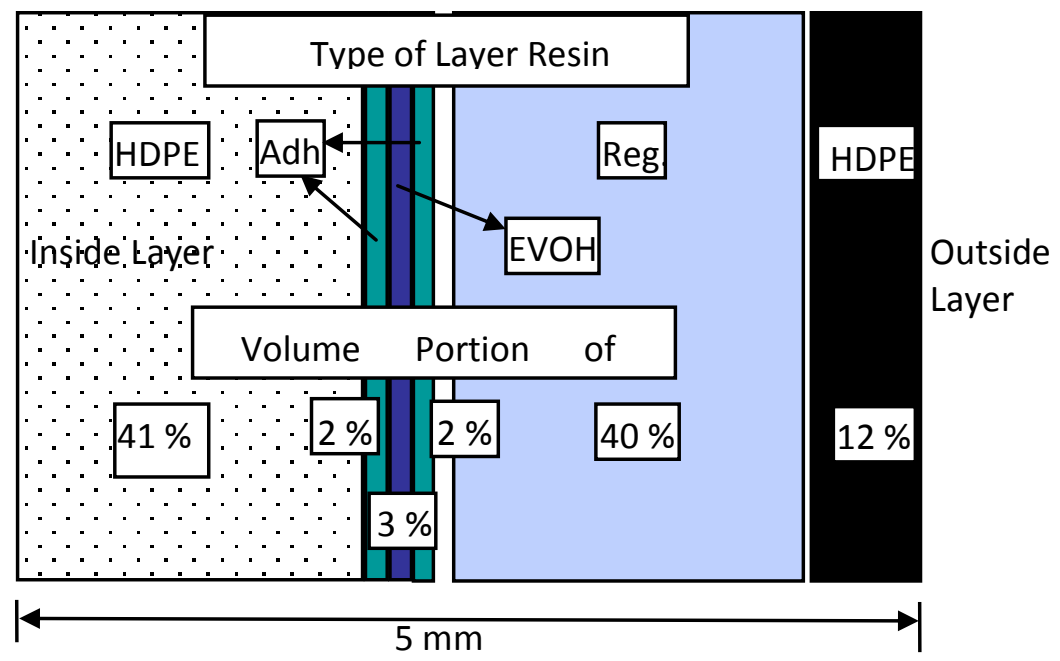

Figure 12 - Multi-layer structure cross section

\subsubsection{Polyoxymethylene (POM) development: Extrusion blow molding (EBM)}

POM is an engineering plastic with the chemical formula -(-O-CH2-)n-. POM is a lightweight, low-friction, and wear-resistant thermoplastic with good physical and processing properties and capable of operating in temperatures in excess of 90 ㅇ․ It is also known as polyacetal, acetal resin, polytrioxane, and polyformaldehyde.

POM is distinguished by a high degree of rigidity and mechanical strength, outstanding resilience, optimal dimensional stability as well as an excellent resistance against a variety of chemicals. Additionally, BASF just recently discovered that POM has excellent barrier properties. Because of these exceptionally positive characteristics, Quantum verified the material's suitability for liner development prior to any additional investment in EBM POM.

\subsubsection{Prototype Liner Testing}

As shown above, (sections 3.2.2.1 and 3.2.2.2) stretched blow molding (SBM) of PEN and PET liners was presented. Additionally, we also molded several nylon liners, using the same mold as the former parts, with internal volume around 1 liter and nominal dimensions as shown in Figure 8. Some trials were carried out to determine the right processing conditions, since we were interested in improving both visual clarity and better drop performance.

Ten containers of each material were manufactured and inspected, and very small deviations were found in the outside dimensions. The same containers were also tested for material distribution thickness in 15 degree increments around the container at three (3) different heights, .75, 2.75, and 5.75 inches. A Gawis thickness measuring gauge from AGR was used for this measurement. The circumferential thickness profiles for each material are graphed below by container height in Figure 13. PET and nylon liners exhibited better thickness distribution than PEN liners. For example, the PEN liners have a circumferential thickness that varies from .037" to .084 " around the 2.75 inch height, a variance of .047". The nylon and PET materials produced a much more desirable distribution, only varying by a maximum of .022" and .019" around the girth, respectively. The thickness distribution depends on material formulation and stretch ratio. The uneven thickness distribution of PEN liners was attributed to insufficient stretch ratio during the molding process. 
DE-FC36-04G014010

Quantum Fuel Systems Technologies Worldwide, Inc

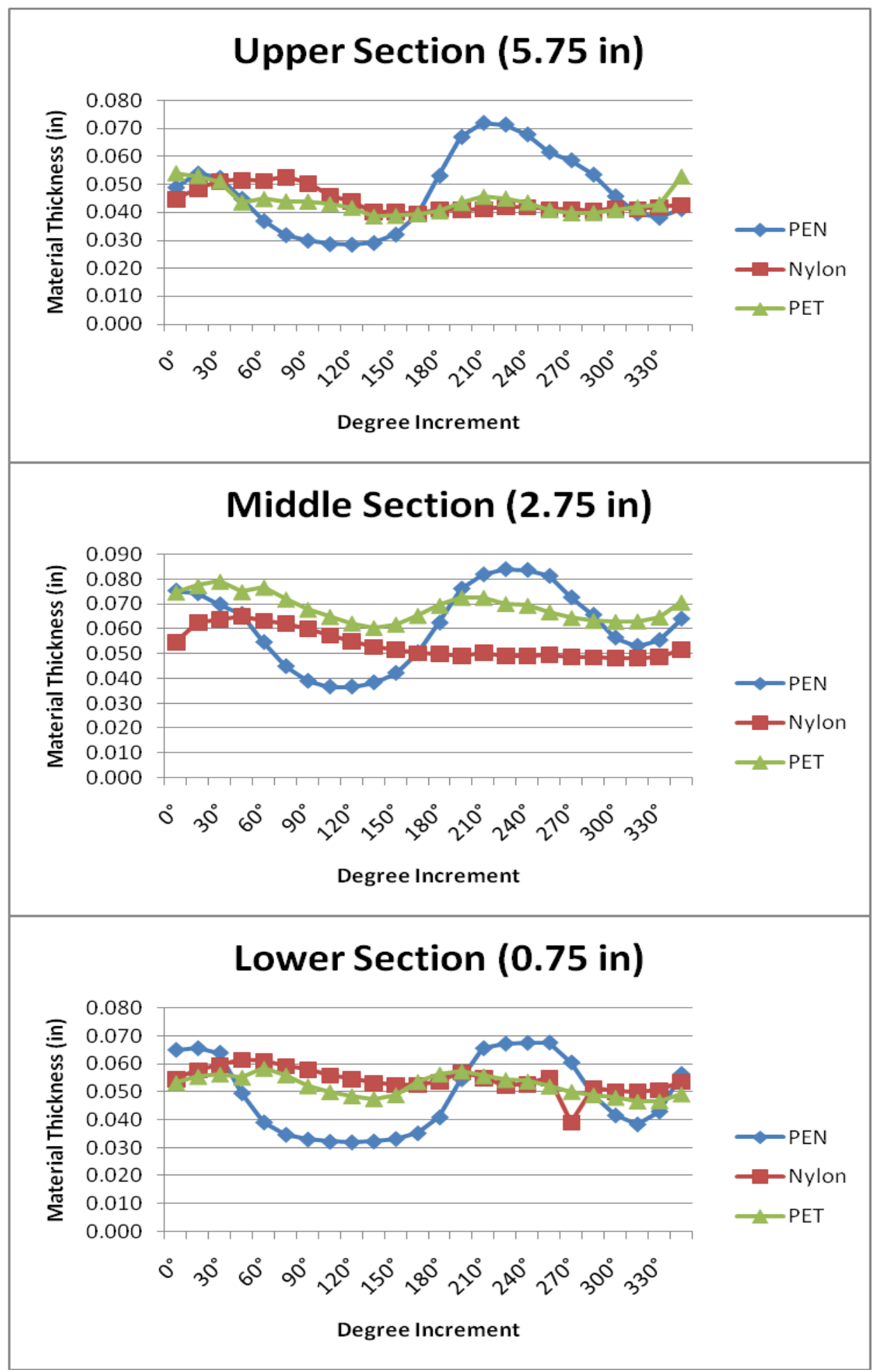

Figure 13 - Liner material thickness distribution

As shown in Figure 13, the liner has a thickness between 1.0-1.5 mm, much thinner than our current HDPE liner ( $5.0 \mathrm{~mm})$, and the barrier performance is still 5 times better than the HDPE liner, based on a permeation model. This barrier performance is one of the key characteristics in choosing liner 
DE-FC36-04G014010

Quantum Fuel Systems Technologies Worldwide, Inc

materials. The other two important characteristics are cycle fatigue resistance and drop impact resistance.

A drop test was performed on 21 water filled $1 \mathrm{~L}$ liners of each material and the pass/fail results at each height were recorded using the Bruceton Staircase method. The containers were filled with water and capped with a custom closure designed and manufactured for the finish. The test was conducted such that each time a container passed a drop, the next container would be tested at a height six (6) inches higher; conversely, whenever a container failed the drop, the next container was tested at a height six (6) inches lower. All containers were dropped vertically, with the base impacting the ground first. The results are shown in Table 3.

Table 3 - PET, PEN and Nylon liner drop impact test results

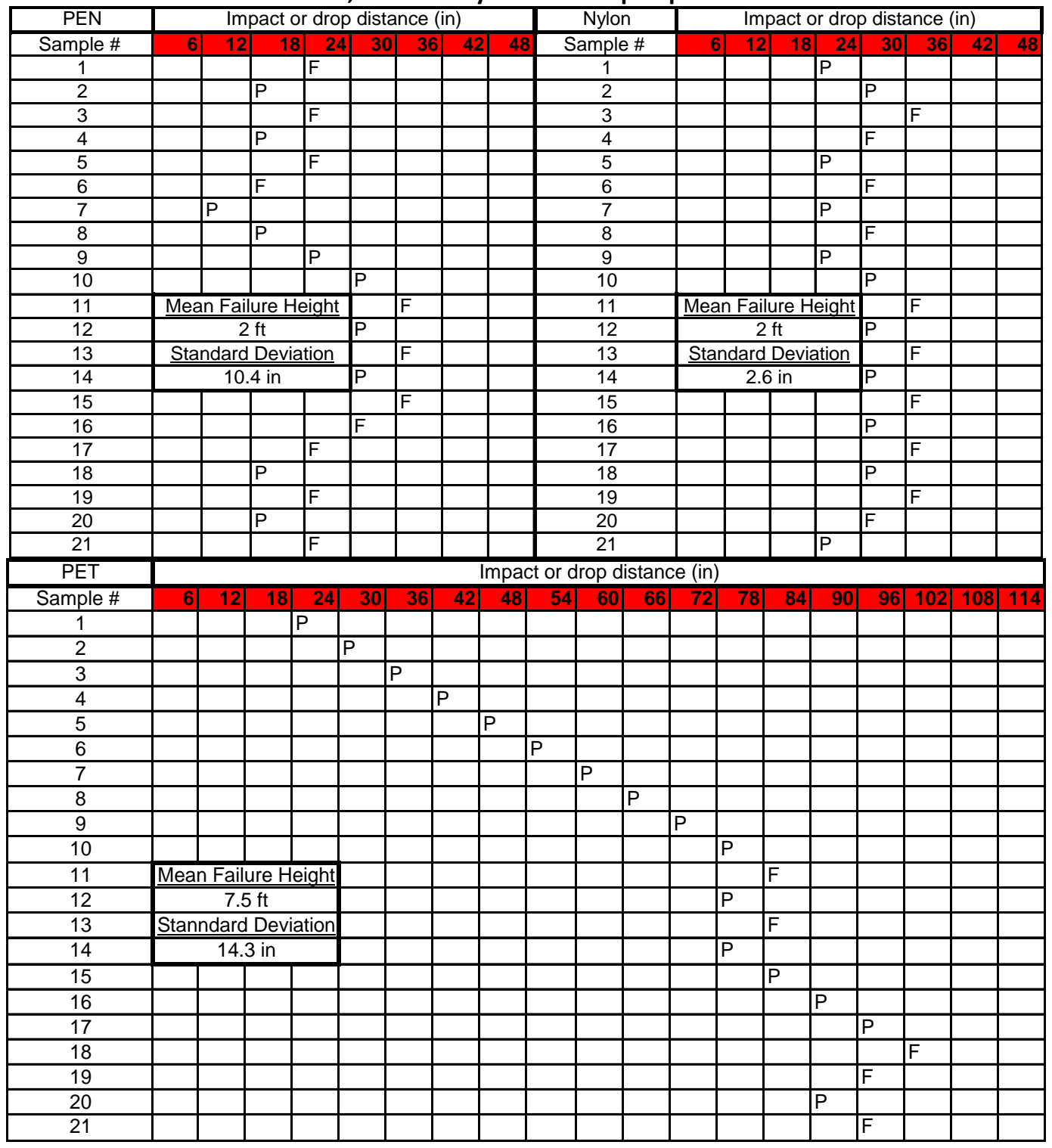

PET liners seemed to exhibit much better toughness or drop impact resistance than PEN and Nylon liners. Compared to PET, PEN has much higher content of benzene rings, which makes it more brittle. The higher number of polar molecules in nylon makes it more brittle than PET. Additional reasons for 
DE-FC36-04G014010

Quantum Fuel Systems Technologies Worldwide, Inc

the results can be attributed to the decreased crystallization in the nylon, which was achieved in the molding process. The failure region for each material was similar.

The PEN liners failed along the thick side, cracking along the edge of the base and propagating along the thick sidewall, as shown in Figure 14. Figure 15 is a collection of failed nylon samples. The typical failure mechanism for this material was very similar to that of the PEN material, a crack several inches long forming along the heel of the container at the radius of the base and then running up the wall of the container. A difference between nylon and PEN is nylon fragmented, whereas PEN merely fractured. A collection of failed PET liners is shown in Figure 16. The typical failure mechanism for this material was a complete fragmentation of the base and gate of the liners. This was perhaps due to the higher velocity of the impact as these containers failed at heights exceeding 7.5 feet. Typical carbonated soft drink containers are required to pass only a 6 feet drop.

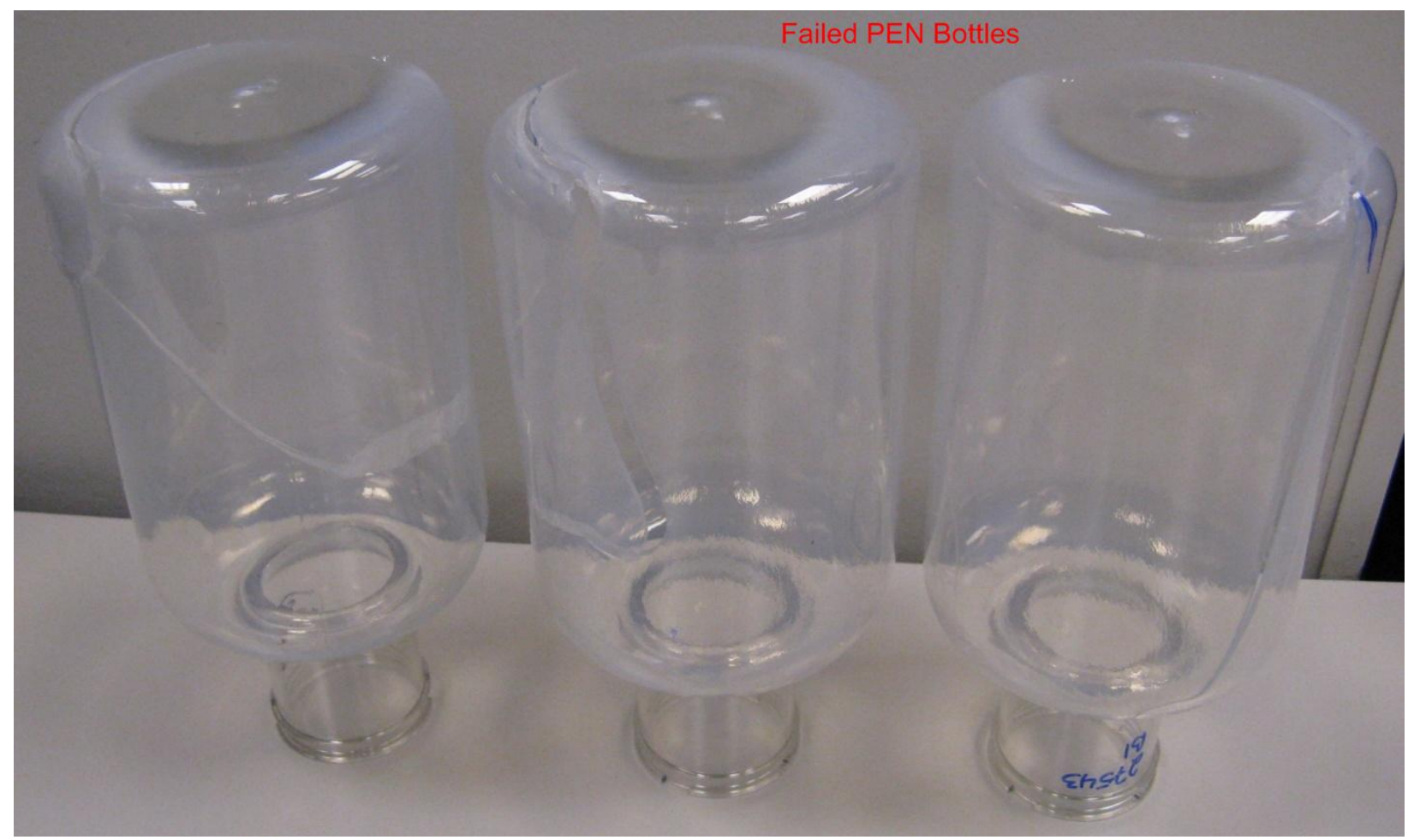

Figure 14 - Failed drop test PEN liners 


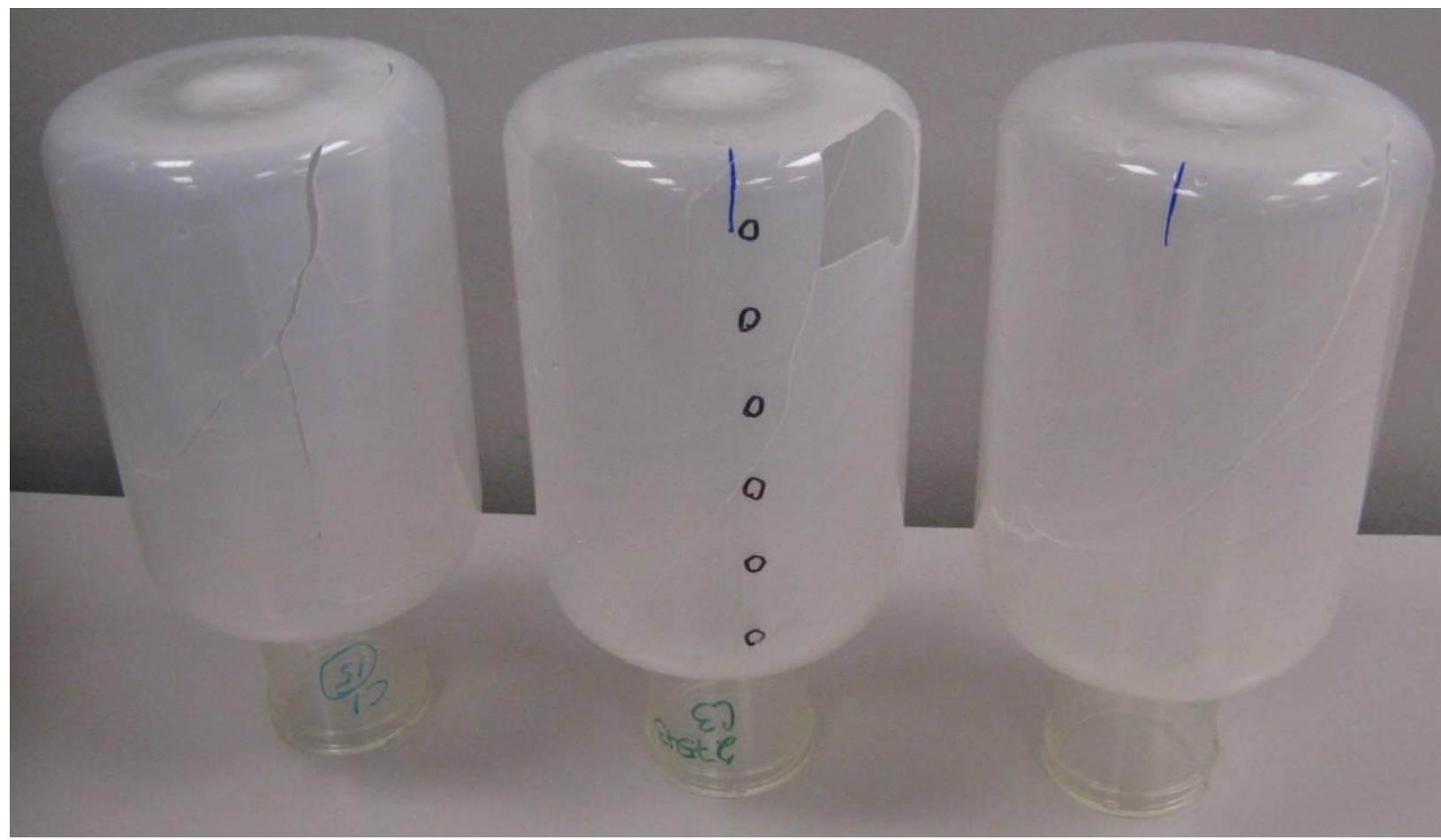

Figure 15 - Failed drop test nylon liners

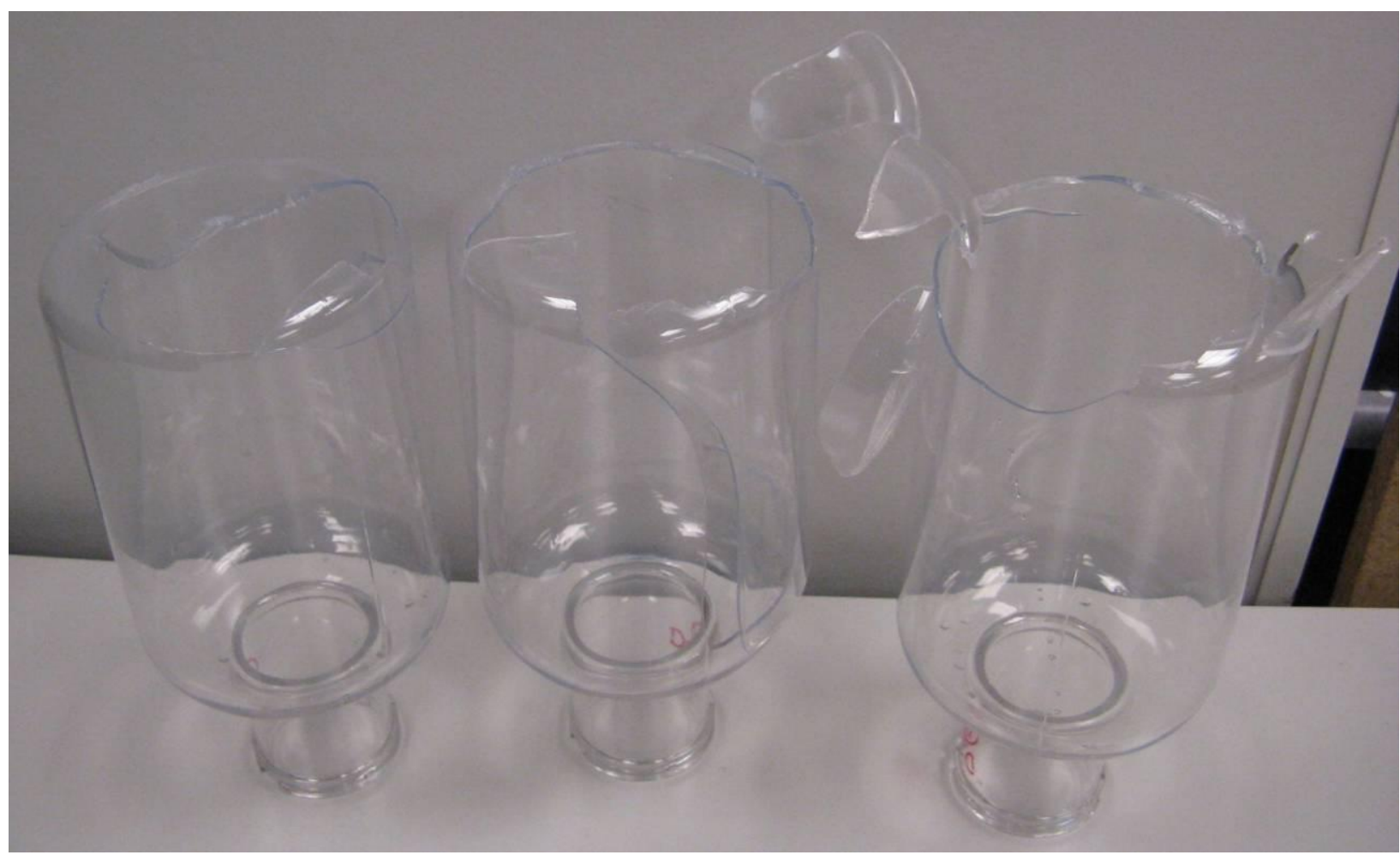

Figure 16 - Failed drop test PET liners

In summary, by using blow molding, we achieved a PET liner with a wall thickness equal to around $20 \%$ of our current HDPE liner with a barrier performance 5 times better than the current HDPE liner. With some molding process optimization, we achieved low crystallization, excellent clarity and drop impact 
resistance for the PET material. As seen from the results, nylon and PEN liners did not perform as well as the PET liners. We learned that the thickness distribution is dependent on the stretch ratio and different materials require different ratios in the SBM process. In addition, there is some trade-off between good barrier performance and impact resistance. Ten four-liter PEN bottles (shown in Figure 9) were made by the SBM process and evaluated. During the evaluation of the liners from the first blow molding iteration, some problems were identified: non-proper liner-metal fitting interface design and reduced toughness due to the sharp transition region from the neck to the body. The initial cycle test failed shortly after starting because the fitting leaked at the liner interface. Substantial effort was made to redesign the fitting so pressure cycle testing could be conducted. We modified the molding condition as well as the liner-metal fitting interface design, for the second iteration. After completing the redesign, the liner completed only a low number of cycles before failing. The failure occurred at the neck of the bottle, where the thickness increased rapidly. Efforts with the vendor were made to eliminate this transition area and it became less drastic but failures remained around thickness transition region during pressure cycling. The best results for pressure cycling from 65 psi to 5,000 were about 7,800 cycles.

Drop testing of the 4-liter PEN liner was performed. The liner was filled with water to about $3.7 \mathrm{~kg}$ and dropped vertically from 5.9 feet high at ambient temperature, so that the bottom touched the ground first. The condition was used to simulate the drop test of the liner inside the composite pressure vessel. The bottom cracked as well as the top section above the thickness transition line, which is shown in Figure 17.
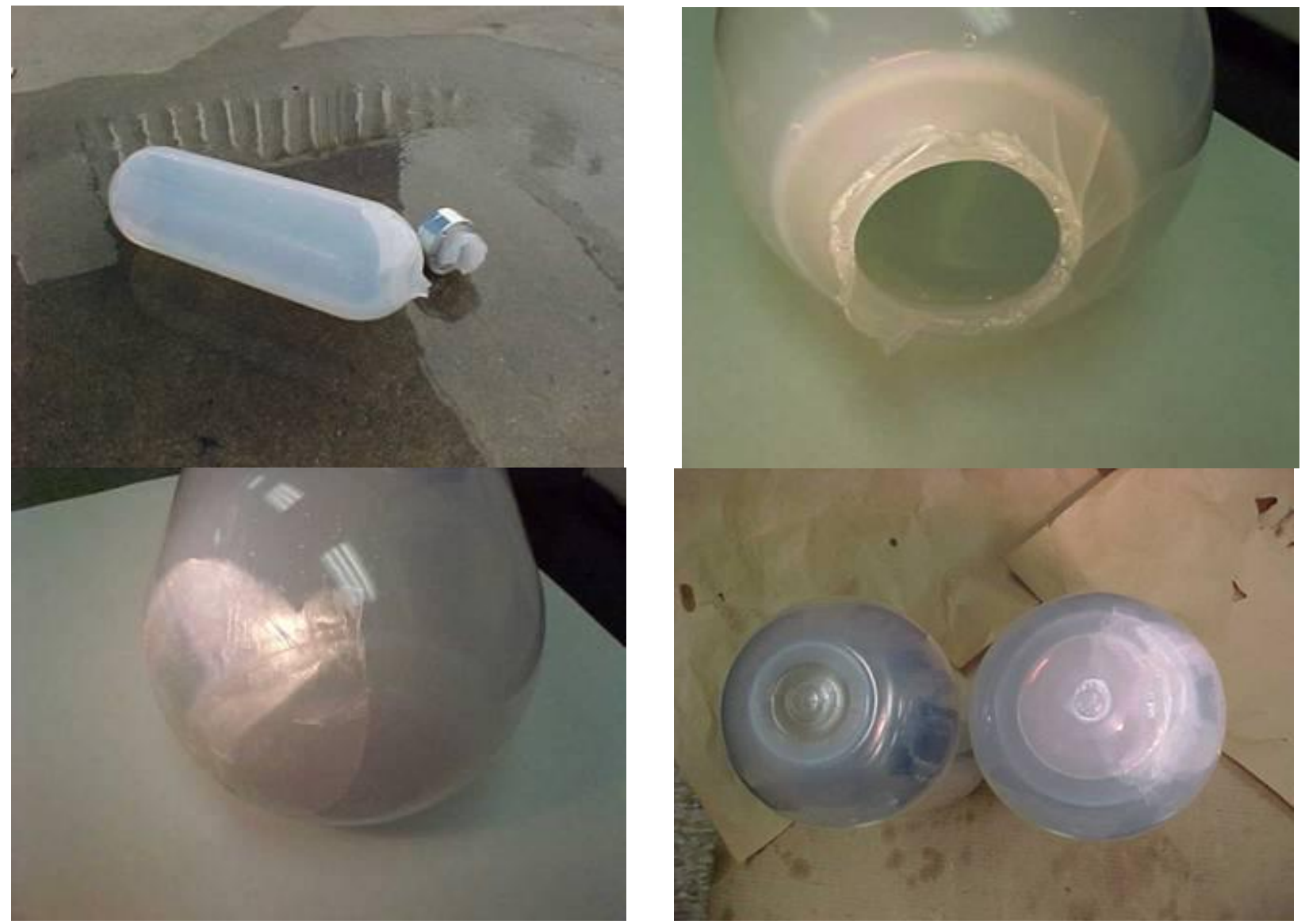

Figure 17- Liter liner drop test 
DE-FC36-04G014010

Quantum Fuel Systems Technologies Worldwide, Inc

\subsubsection{Multi-layer Liner Material Evaluation}

We have discussed the work on multi-layered material structures. Both static tensile and fatigue tensile properties were evaluated at room temperature and at -40 으. All specimens behaved in a very ductile manner in each of the static tensile tests. Samples yielded at about $8.5 \%$ strain and didn't fail completely, although delamination happened at about $100 \%$ strain. No obvious damage was found on any specimen during cycle fatigue testing. Therefore, the material toughness and delamination resistance under mechanical load is deemed acceptable. Some of the multi-layer material panels were sent out to a third party lab for delamination resistance testing during hydrogen gas pressure cycling.

The testing is necessary because of our concern that under hydrogen gas depressurization, the hydrogen gas molecules accumulated along the HDPE / PVOH interface could produce back pressure and tear the material along the interface.

In addition, permeability measurement equipment was designed in-house, and the validity of this equipment was confirmed by comparing the measured HDPE permeability with the published data in [2], using Helium. Permeability data of POM relative to Helium was then measured. POM permeability relative to Helium is about 5 times lower than HDPE, so the liner made of POM can be much thinner than the HDPE liner. However, it was found that POM is more brittle than HDPE. When we used a piece cut with a die to make a sample for permeability test, around the edge of the sample micro-cracks were found on the POM and none on the HDPE. This causes concern about the toughness of POM.

Based on the measured results for the liner candidate materials and the data from references, we consider PET and PEN as the best liner candidate materials for blow molding process. Other materials show very good performance according to some requirements; but cause concerns in others. For example, POM and Nylon seem to have much lower permeability than HDPE, but show brittleness especially at low temperatures.

\subsubsection{Evaluation of the Liners made from Blow Molding Process}

We discussed the 1-liter liners made by stretched blow molding (SBM) process: PET, PEN and Nylon. Quantum evaluated these liners and identified some problems with PEN and Nylon: uneven thickness distribution and reduced toughness compared to our current HDPE liners. With limited funding, we focused on PET for the liner. We designed a steel test pot to match the liner profile, the PET liner was placed inside the test pot and pressure cycled according to EIHP standards. The test pot is shown in Figure 18. Ambient Temperature Pressure Cycling Test was performed from 1.5 MPa to 87.5 MPa at a rate of $5 \sim 6$ cycles per minute until failure. In the test set-up, the pressure was generated using an organic oil, and failure can be detected instantaneously once oil leakage is found. The leakage was detected at cycle number $=21,542$, satisfying EIHP requirement that the liner shall not fail before reaching 15,000 cycles. The leakage happened at the transition region between liner neck and main body, due to the sharp transition in thickness resulting in local stress concentration. With proper molding the performance in the ambient pressure cycle fatigue experiment is expected to improve. 
Quantum Fuel Systems Technologies Worldwide, Inc

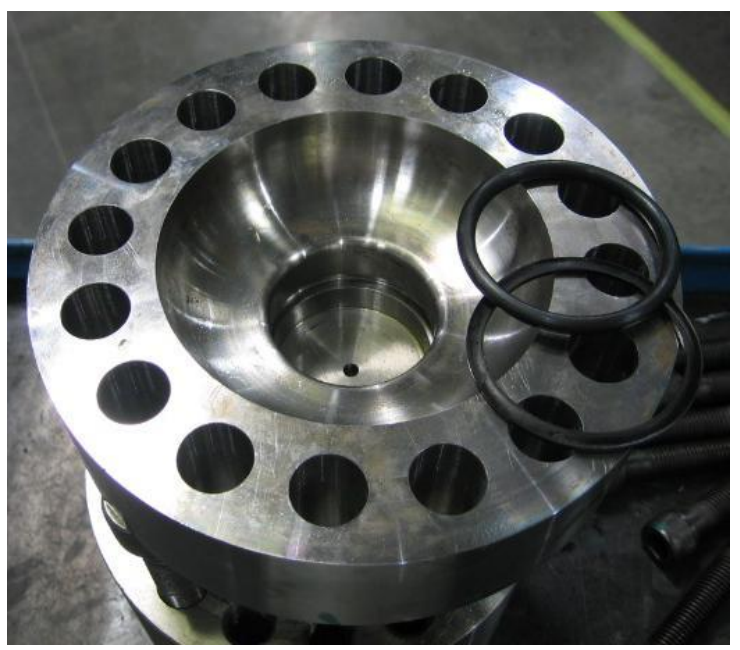

(a) Top part

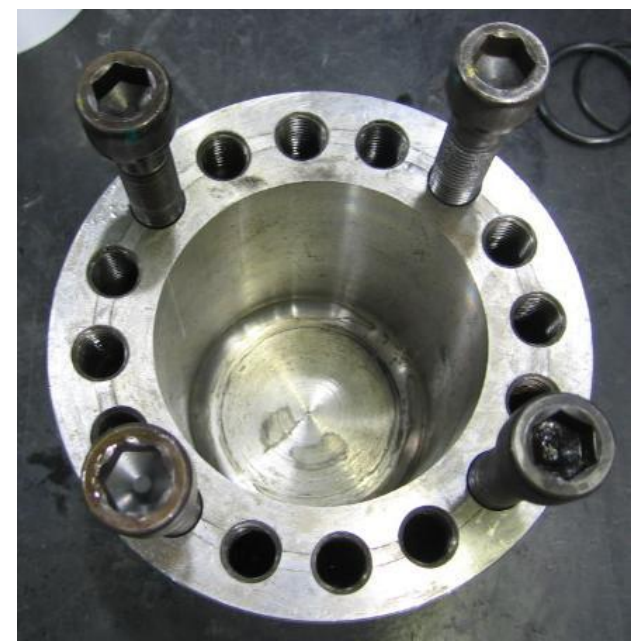

(b) Bottom part

Figure 17 - Test pot for 1-liter pressure cycle experiment

Currently polymer liners for high pressure applications are manufactured by rotational molding and injection molding. Compared to rotational molding, blow molding offers more precise control on liner thickness, more material choices, shorter production cycle time (a few minutes versus a few hours) and higher automation. Blow molding also has advantages over injection molding in liner production. In injection molding it is difficult to make large vessels due to the size of the parison being too difficult to form. Typically what is done is to limit the size of the parts being made to within standard injection molding limits and then weld sections together to form larger parts.

\subsubsection{Liner Material Conclusion}

Summarizing the achievements in liner development, we found right candidate materials to use for liner blow molding process, and evaluated blow molded liners. With $80 \%$ reduction in liner thickness out of the blow molding process, using PET material, we have demonstrated excellent barrier performance, toughness and cycle fatigue resistance from evaluation of prototyped liners.

\subsection{Track 3 Objectives- Metal Fittings Development}

A cost and weight analysis of the metal fittings was performed utilizing classic finite element analysis modeling methods. The results were used to optimize and evaluate alternative designs that interface with the updated liner. Time and budget expired before testing of the updated design could be conducted.

\subsubsection{Literature review}

The most important factors for metal fitting candidates are yield strength, fatigue life, and hydrogen embrittlement. There are well published data on the first two properties for most common metals under normal conditions. The third factor significantly affects the first two under a hydrogen environment. An additional factor to consider is cost. Per the project scope, Quantum redesigned the components to improve cost efficiency and weight efficiency of the hydrogen gas storage vessel. Part of the due diligence was to test the components to ensure that the yield strength, fatigue life and other 
important mechanical properties meet current requirements. One important test that was not captured as part of the scope is to test in a hydrogen environment.

Hydrogen embrittlement, also called hydrogen grooving, is the process by which metals, most importantly high-strength steel, become brittle and crack following exposure to hydrogen. The mechanism starts with lone and very-small-sized hydrogen atoms diffusing through the metal. The solubility is a function of temperature in that it increases with the latter, and the diffusion rate also depends on the hydrogen concentration and pressure differential. These hydrogen atoms re-combine in minuscule voids of the metal matrix to form hydrogen molecules, and create pressure inside the cavity. This tears the metal, reduces the strength and toughness and finally cracks the material.

The mechanism of hydrogen embrittlement is quite complex and there are numerous publications studying this phenomena. We briefly summarize the conclusions from some very comprehensive studies. The effect of hydrogen embrittlement was found to be greatest with shortest hold time in hydrogen environments ${ }^{57}$. Studies have found that embrittlement degrades the mechanical properties of susceptible metals much more at 1 hour exposure time than at longer times. Therefore, embrittlement happens very fast, but the relationship between the degree of embrittlement and exposure time is not fully understood. The degree of embrittlement was also found to be independent of stress level applied on the specimens during hydrogen exposure. However, the dependence on hydrogen gas pressure level is unclear, since embrittlement degraded the notched strength more at higher pressures but didn't degrade the un-notched strength. It seems that surface imperfections are very sensitive to hydrogen embrittlement. The critical stress intensity factor $\mathrm{K}_{\mathrm{IC}}$ decreases significantly as the pressure increases ${ }^{58} 5061$. Under hydrogen environment, hydrogen gas temperature affects the material toughness significantly, in that the loss of ductility due to thermal precharging of hydrogen is significantly larger than that due to ambient temperature precharging of hydrogen ${ }^{62}$.

Under the same hydrogen immersion condition, hydrogen embrittlement degrades different metal materials in quite different ways ${ }^{57}$. High strength steel and nickel based alloys are extremely sensitive to embrittlement, in that the ductility reduction was as much as $84 \sim 92 \%$, as soon as these materials contacted hydrogen. Ductile and lower-strength steels, pure nickel, and titanium based alloy were severely embrittled. They had a considerable reduction of notch strength and ductility (15 45\%) but no reduction of un-notched strength. Stainless steel (SS) AISI type 304L, 305, beryllium copper and commercially pure titanium were slightly embrittled. These materials had a small decrease of notch strength and a negligible decrease of unnotched ductility. The last category of materials, which experienced negligible reduction of both notched and unnotched strength and ductility under hydrogen environment, included SS AISI 310, SS AISI 316, SS AISI 316L, SS A-286, Aluminum (AI) 7075 T-73, AI 6061 T-6, Al 1100-0 and OFHC Copper. These are the ones we decided to focus on. The results were confirmed by other studies ${ }^{63}$, which found that high-strength and low-alloy steels, nickel and titanium alloys are most susceptible to hydrogen embrittlement and aluminum and beryllium copper alloys are some of the least susceptible to hydrogen embrittlement along with a few other metals.

For the same material, processing conditions affect hydrogen embrittlement significantly since it affects the surface quality. Coatings can also provide a protective barrier to hydrogen. For example, the native oxide on Aluminum surfaces acts as a kinetic permeation barrier to hydrogen since the kinetics of

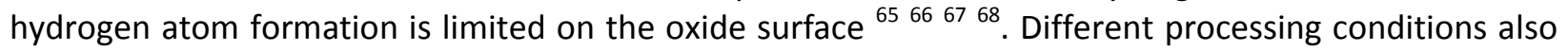
change the distribution of different phases in the material, dislocation density and stacking faulting energy. SS 316 shows larger hydrogen susceptibility when sensitized ( $973 \mathrm{~K}$ for 24 Hour) compared to solution-annealed microstructures ${ }^{69}$. Derivatives of some of the hydrogen resistant materials were 
DE-FC36-04G014010

Quantum Fuel Systems Technologies Worldwide, Inc

developed for special hydrogen environment applications. The Chinese HY-1 alloy steel is reported to be resistant to hydrogen embrittlement, and has a similar composition to nickel-rich SS $316^{70}$. SS JBK-75, based on SS AISI 316L, was developed to improve the weldability and resistance to hydrogen embrittlement $^{71}$. SS NASA-HR-1, based on JBK-75, has improved strength and resistance to hydrogen embrittlement, oxidation and corrosion ${ }^{72}$.

Other factors besides hydrogen embrittlement have to be considered as well. For example, once copper is oxidized it is very easy for hydrogen to attack and embrittle the material ${ }^{59}$. Copper is much softer than Aluminum and steel, and easy to deform under stress, which disqualifies it as a candidate for metal fitting material. Compared to Al 6061 and 7075, Al 1100 has a much lower ultimate strength and yield strength, which also disqualifies it as a candidate. Cost of the material needs to be a factor.

\subsubsection{Metal Fitting Prototype Parts}

Metal fittings based on the literature study and detailed FEA and design team analysis for an adapterless tank design were ordered. These parts included; the 316L stainless steel boss with a 0.9 inch opening (see Figure 19); a test plug that simulates the ports and surfaces of a valve body; and a modification to the rotational molding tool to create the geometry in the liner for the interface to the boss.

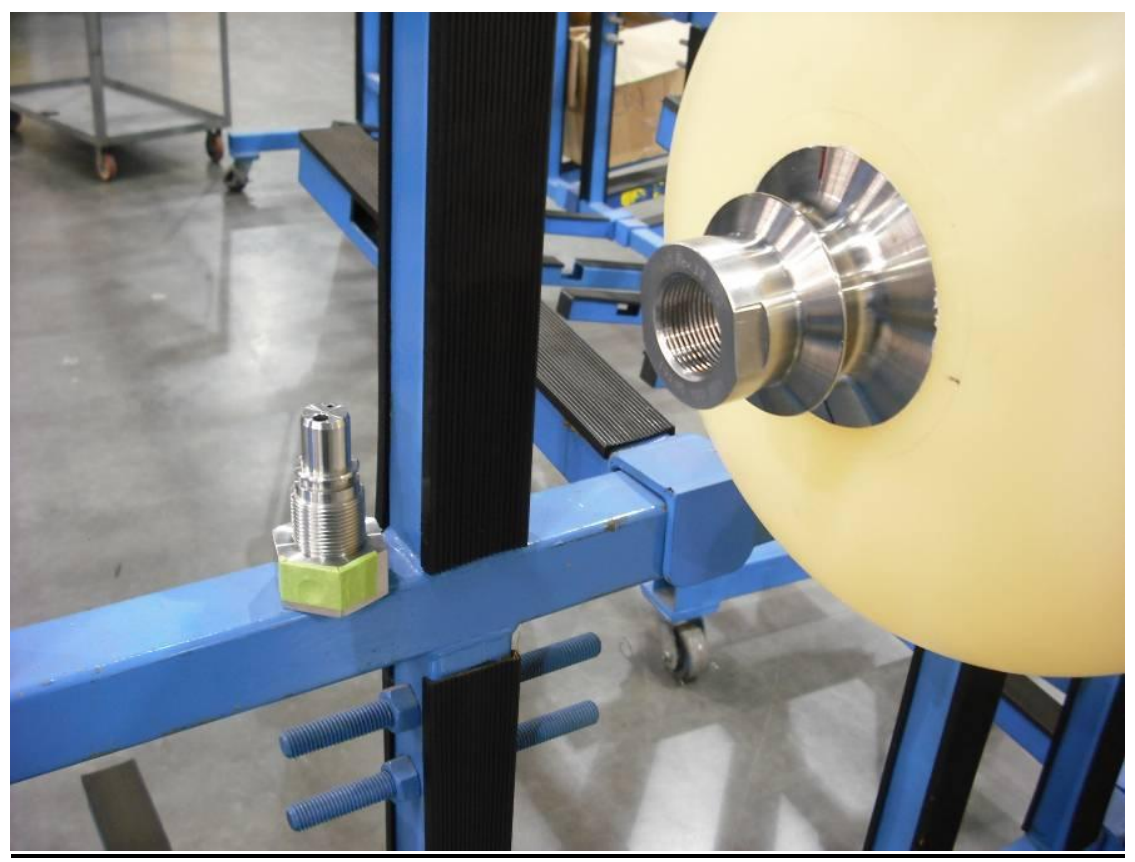

Figure 18 - Stainless Steel Adapterless Liner and Valve Body

The steel boss design included sealing surfaces for interfaces to the polymeric liner and the valve interface. Testing of the seal design was performed earlier on subscale test pots and proved to be effective over the temperature and operating range for the hydrogen pressure vessel. However, full testing of the subscale test pot was not completed due to a small crack that developed in the lid of the test pot. This crack is believed to have been initiated during the manufacturing of the test pot or flaws in the raw material and not due to the tests that were performed on the test pot. This conclusion was based on testing conducted on another test pot with equivalent thicknesses with no crack initiations. 
DE-FC36-04G014010

Quantum Fuel Systems Technologies Worldwide, Inc

During initial design of the boss, considerations for transmitting torsional loads from the boss to the liner during manufacturing were explored. However, due to time and budget constraints, torque transmission features of boss to liner interface were not incorporated and, for purposes of proof of concept, adhesives were used to temporarily bond boss to liner during the winding operation. After winding, bonding between liner and boss is not needed for operation or service because the flats on the boss transmit loads directly to the composite. This will allow the liner to rotate within the boss and composite, but is expected not to affect function of sealing surfaces. When the tank has even a small amount of pressure, it is expected that the liner will not be able to turn due to the coefficient of friction between the liner and the composite shell.

In addition to the stainless steel parts, 6061-T6 parts were ordered for comparative purposes. These aluminum parts required significant redesign from the stainless steel parts in order to meet strain and fatigue requirements. It also required the reduction of the opening from 0.90 inch to 0.65 inch.

Liners for the stainless steel boss were manufactured and adhesives to bond the HDPE liner to the boss during manufacturing of the tank were being tested. However, the project ended prior to being able to wind a full scale tank and test the design.

Quantum plans to continue development of this design and we expect it will have a significant cost reduction for gaseous hydrogen storage tanks. This combined with blow molded liners is expected to make significant progress towards DOE goals.

\subsection{Composite Manufacturing Process Parameter Optimization}

A design of experiments was conducted using four parameters at two levels. The four parameters were selected based on a brain storming session with a cross functional team consisting of design engineering, manufacturing engineering, quality, and operations. The parameters were then ranked by how significantly they affected the tank performance and their ability to control production. From this the highest four factors were chosen. The factors that were chosen are wind speed, tension, resin bath location (fiber angle in and out of bath), and liner pressure. Twenty four tanks were built based on a Taguchi half fraction design of experiments (DoE). Three tanks using standard manufacturing parameters were also built to compare to the results of the DoE. The tank selected for the DoE is a 34 liter tank with five layers of composite. The design burst pressure is 5,000 psi. Response for the design of experiment is the burst pressure of the tank. Length, diameter, and weight of each tank are also being recorded and will be analyzed to see if there is an effect on burst pressure.

The 34L tank was chosen in order to more easily show effects of the DoE. By having a lower burst pressure, variation in the burst is not as likely to be part of standard variation of results seen in high pressure tanks (70 MPa service pressure). This also allowed for reduced usage of materials and labor to conduct the DoE. The results of the design of experiments showed that no item that we tested was statistically significant (see Table 4 and Figure 20). 
Table 4 - Result of Manufacturing Design of Experiments

\section{Factorial Fit: Burst Pressure versus Tension, Wind Speed, ...}

$\begin{array}{lrrrrr}\text { Estimated Effects and Coefficients for Burst Pressure (coded units) } \\ \text { Term } & \text { Effect } & \text { Coef } & \text { SE Coef } & \text { T } & \text { P } \\ \text { Constant } & & 5069.00 & 43.33 & 116.98 & 0.000 \\ \text { Tension } & 70.33 & 35.17 & 43.33 & 0.81 & 0.429 \\ \text { Wind Speed } & 102.67 & 51.33 & 43.33 & 1.18 & 0.253 \\ \text { Liner Pressure } & -114.33 & -57.17 & 43.33 & -1.32 & 0.206 \\ \text { Bath Location } & -158.67 & -79.33 & 43.33 & -1.83 & 0.086 \\ \text { Tension*Wind Speed } & -153.00 & -76.50 & 43.33 & -1.77 & 0.097 \\ \text { Tension*Liner Pressure } & -43.00 & -21.50 & 43.33 & -0.50 & 0.627 \\ \text { Tension*Bath Location } & 96.67 & 48.33 & 43.33 & 1.12 & 0.281 \\ & & & & & \end{array}$

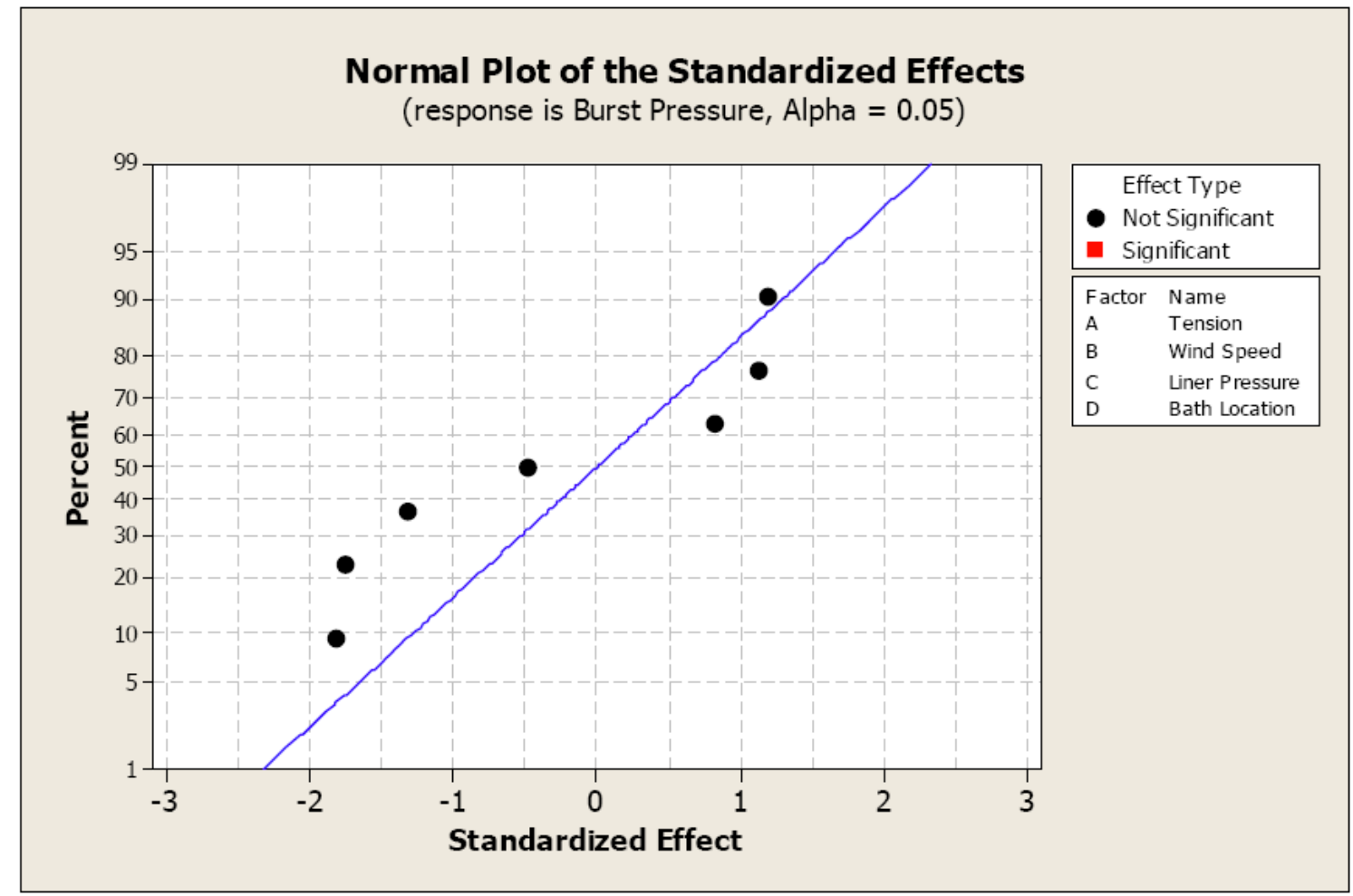

Figure 19. Results of Design of Experiments

However, the factors that showed the greatest affect on burst performance were resin bath location followed by the combination of tension and wind speed. Even though "Bath Location" and a combination of "Tension and Wind Speed" are more significant than other factors, the lack of repeatability in burst pressure is one of the main reasons for not having a significant factor (standard deviation for the repeat runs is as high as $303 \mathrm{psi}$ ).

Figure 21 shows to have the maximum burst pressure we should have:

a) Tension: high 
DE-FC36-04G014010

Quantum Fuel Systems Technologies Worldwide, Inc

b) Wind Speed: high

c) Liner Pressure: constant

d) Bath Location: close to payout

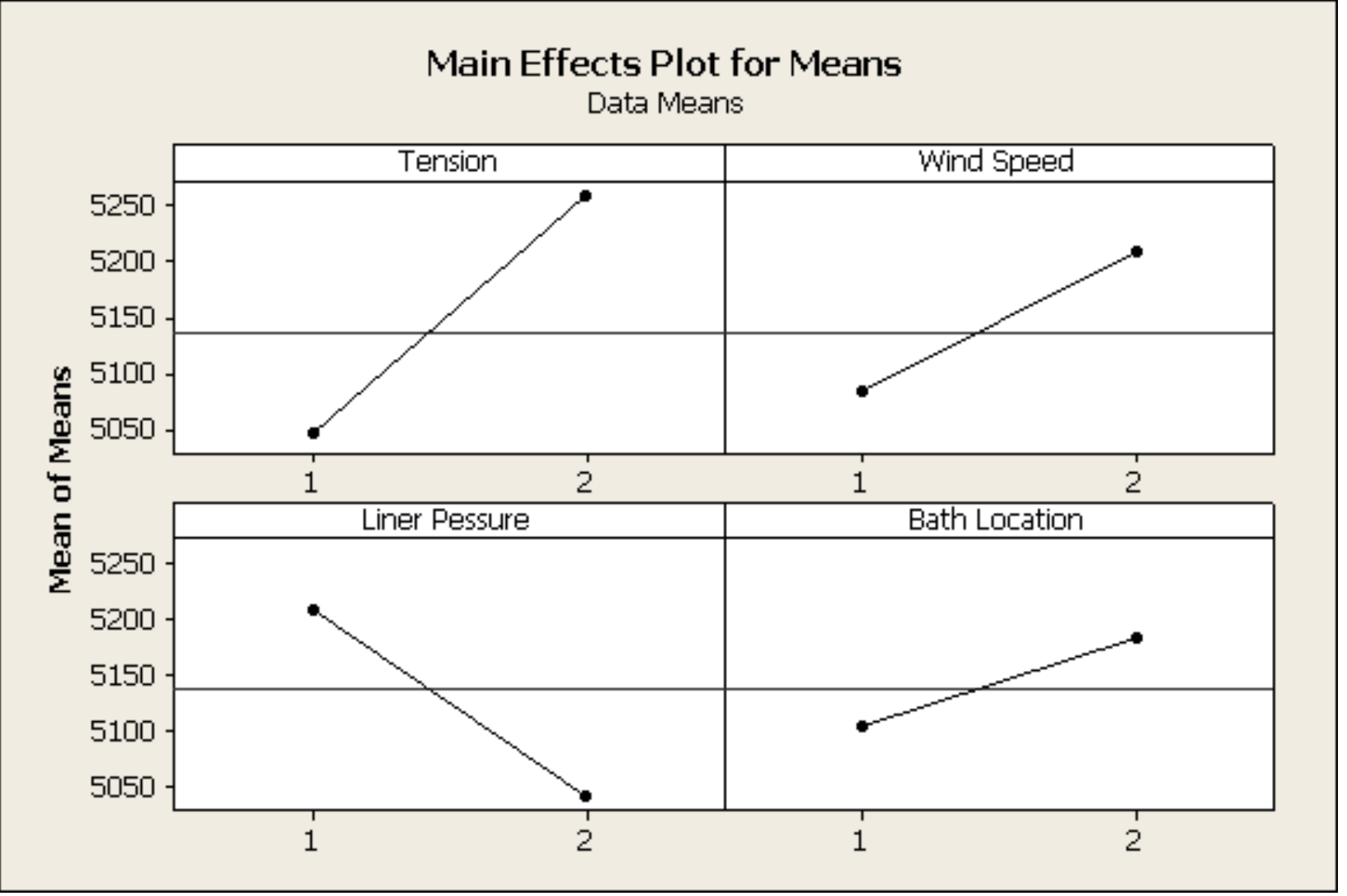

Figure 20 - Average Result from Inputs

Recommendations are to rerun the design of experiments focusing on one or two factors, also looking at other factors that may have influence on results that were outside of the design of experiments. These factors may include operator, temperature in manufacturing facility at time of winding, duration between wind time and final cure, size of spool in creel cabinet, etc.

\subsubsection{Alternative Fiber Evaluation}

During 2009 a new glass fiber was introduced by Owens Corning. This new R-glass brand named " $X-$ Strand" has material properties similar to S-glass with improved corrosion resistance and pricing closer to E-glass. Quantum has been working with Owens Corning to evaluate this new fiber and determine if it will be cost effective as an alternative material from the carbon fibers we are currently using.

Initial evaluation was done using 4 tows of glass each with 7 ends collimated onto each spool giving a Tex of 2520. This fiber was respooled at Owens Corning laboratory and supplied to Quantum. The fiber was evaluated on a $104 \mathrm{~L}$ tank that previously was designed using carbon fiber for a 3600 psi application. The intent is to do a cost comparison of the glass and carbon tanks.

The first tank burst at the aft end with a pressure of 9,310 psi. To properly evaluate the performance of the tank it had been designed to burst mid cylinder where stresses are more uniform. Since the tank did 
DE-FC36-04G014010

Quantum Fuel Systems Technologies Worldwide, Inc

not burst in the middle the wind layup was redone in order to make a more conservative design with stresses in the middle approximately two times higher than those seen in the domes.

A second tank was wound with this new design. During the winding of the second tank, it was observed that loose stands of fiber were seen between the creel cabinet and the resin bath. These loose fibers when wound onto the tank will provide no structural strength and may in fact act as voids in the composite structure significantly reducing tank performance. It is believed the loose fibers were caused by the joining of several ends onto a single spool during the rewinding. At this time Owens Corning was not set up for production of this product and there might be mismatches of tension on each of the ends as it was wound onto the spool.

This tank also burst at the aft end at 10,994 psi. Quantum discussed the observations and results with Owens Corning and it was decided to try the new fiber from their production line that had recently been started. This changed the fiber to a 9 micron fiber with only two ends combined on each spool with a Tex of 675. In order to be able to use the programs that were developed for the higher Tex fibers, Quantum increased the number of tows being wound from 4 to 14.

Burst result for the new tank showed a failure in the forward end of the tank at 12,200 psi. Based on fiber usage and cost differential between carbon and Owens Corning X-Strand glass, it is estimated that the cost savings can be $-116 \%$.

The cost saving is based on using a safety factor of 2.25 for the carbon tank and a factor of safety of 3.5 for the glass. The difference in the design factor of safety is due to the strength reduction seen in normal $\mathrm{E}$ and $\mathrm{S}$ glasses. With Owens Corning new $\mathrm{X}$-strand glass it is believed that stress corrosion cracking which is the primary degradation of glass will be significantly reduced. Owens Corning and Quantum Technologies are continuing the investigation of fiber life degradation for the X-Strand fibers. If it can be proved that the strength loss over the life of the fibers is no worse than carbon fiber, then the same design criteria of 2.25 factor of safety could be used. This would give a cost savings of $-39 \%$ from a similar carbon fiber tank. From these results the new glass fiber does not appear to be a good alternative to Quantum's current carbon fiber.

\section{Conclusions}

Over the course of the program Quantum has evaluated many areas to meet DOE Freedom Car goals. In some of these areas we have met and exceeded the goal such as gravimetric efficiency with a 129L $10,000 \mathrm{psi}$ fuel storage system having a gravimetric efficiency of $2.13 \mathrm{~kW}-\mathrm{hr} / \mathrm{kg}$. Quantum has not met the cost efficiency and volumetric efficiency goals, but during this study significant progress has been made towards them.

Cost efficiency is still the major barrier for full commercialization of high pressure compressed hydrogen as a viable alternative energy for automotive use. In table 5, Quantum's status is calculated based on a system, which includes a single 129 Liter type IV $\mathrm{H}_{2}$ tank (approximately $5 \mathrm{~kg}$ hydrogen capacity at 10,000 psi service pressure) with a solenoid valve (AOTV), a set of high pressure and low pressure regulators, a mid stage valve (MSV), a receptacle with filter, all tubing and fittings for this system, a frame, a wire harness, a pressure sensor and a balance of parts (consisting mainly of fasteners etc). The end-user cost efficiency is calculated based on an assumption of 500,000 units/year, and the assumption that $1 \mathrm{~kg}$ hydrogen is able to generate $33.3 \mathrm{kWh}$ energy. Per the DOE request, we performed a cost analysis for 10,000 and 100,000 and 500,000 units/year. The cost efficiency is approximately $\$ 54.1 / \mathrm{kWh}$ and 
DE-FC36-04G014010

Quantum Fuel Systems Technologies Worldwide, Inc

$\$ 48.1 / \mathrm{kWh}$ for the first two cases respectively, with the last case shown below in Table 5. In table 5, DOE 2010 target is from the Hydrogen, Fuel Cells and Infrastructure Technologies Multi-Year Research, Development and Demonstration Plan (MYPP). This plan can be accessed at http://www.eere.energy.gov/hydrogenandfuelcells/mypp/

Table 5 - Progress towards Meeting Technical Targets for 500,000 unit per year On-Board Hydrogen Storage for Light-Duty Vehicles

\begin{tabular}{|l|l|c|c|}
\hline Storage parameters & Units & $\begin{array}{c}\text { DOE 2010 } \\
\text { Target }\end{array}$ & Quantum Status \\
\hline System Gravimetric Capacity & $\mathrm{KWH} / \mathrm{Kg}$ & 1.5 & 2.13 \\
\hline System Volumetric Capacity & $\mathrm{KWH} / \mathrm{L}$ & 0.9 & 0.83 \\
\hline System Cost & $\$ / \mathrm{KWH}$ & 4 & 45.9 \\
\hline
\end{tabular}

Through co-operation with the Department of Energy and Automotive OEM's, Quantum Technologies has made significant progress towards viable automotive systems. Quantum continues working with its partners to develop this technology and progress towards the DOE 2015 goals.

\section{Publications}

1 H2 Tank Manufacturing Optimization, Annual Merit Review, Department of Energy, June 9 13, 2008, Arlington, VA

2 Low-Cost High-Efficiency High-Pressure H2 Storage, Annual Merit Review, Department of Energy, May 18 22, 2009, Arlington, VA

\section{Patents}

\section{Disclosure in process for Metal Fitting for filament wound pressure vessel, no Patent\#.}

\section{References}

1 S. P. Timoshenko, J. N. Goodier, Theory of Elasticity, 3rd Edition, McGraw-Hill Book Company, pages 68-71

2 http://www.flextank.com.au/PDF_Files/Gas_Barrier_Properties.pdf, retrieved on September29, 2008

3 Flodberg G., Hojvall L., Hedenqvist M. S., Sadiku E. R., Gedde U. W., Barrier properties of blends based on liquid crystalline polymers and poly(ethylene terephthalate), International Journal of Polymeric Materials, 2001, vol. 49, pp. 157-177

4 Patent, US 5464106 Multi-layer containers

5 Patent, US 4578295 High barrier polymer blend and articles prepared therein

6 Patent, WO 9932403, Polyester nano composites with dispersed expanded cation-exchanged clay materials for high gas barrier applications

7 DOE Hydrogen Program, FY 2005 Progress Report, V.A.2 New Materials for Hydrogen Pipelines, Oak Ridge National Lab

8 Nanocomposites derived from sulfonated poly (butylene terephthalate), Macromolecules, 2002, vol. 35, no. 14, 5508-5516

9 Patent, US 5336549, Biaxially oriented laminated Film

10 Patent, US 2824019, An oriented heat-set polyethylene terephthalate film coated with a plasticized nitrocellulose resin containing a sulfonamide-aldehyde resin

11 Patent, US 4363840, Packaging films, sheets and blown or moulded hollow bodies

12 Patent, US 4372986, Polyvinyl alcohol-clad shaped article of vinyl chloride resin

13 Patent, US 4544698, Polymer coating composition and its use in the manufacture of layered packaging 
14 Patent, US 4239826, Multi-layer barrier film

15 Patent, US 3309330, Coated particles of vinylidene chloride copolymers

16 Patent, US 4515836, Process for coating substrates with aqueous polymer dispersions

17 Patent, US 5489455, Container with polyamine-polyepoxide gas barrier coating

18 Patent, US 5472753, Polyethylene terephthalate-containing laminate

19 Patent, WO 99/20462, Barrier-coated polyester

20 Permeability of $\mathrm{N} 2, \mathrm{Ar}, \mathrm{He}, \mathrm{O} 2$ and $\mathrm{CO} 2$ through biaxially oriented polyester films - dependence on free volume, Polymer, 2001, Vol. 42, p. 2413-26

21 Oxygen-Barrier Properties of Cold-Drawn Polyesters, Journal of Polymer Science: Part B: Polymer Physics, 2002, Vol. 40, No. 9, p. 862-877

22 Necking mechanism and its elimination in uniaxially drawn films of poly (ethylene naphthalate) (PEN) / polyetherimide (PEI) blends, Journal of Applied Polymer Science, 1997, Vol. 65, no. 11, p. 2059-2074

23 Polyamide pipes approaching practical use in high-pressure sector, E. ON Ruhrgas AG, Dorsten, Germany. 3RD International, 2007, vol. 46, No. 4, page 220-226

24 Preparation of High Barrier and Exfoliated-type Nylon-6/Ultrafine Full-Vulcanized Powdered Rubber/Clay Nanocomposites. Macromolecules, 2005, Vol. 38, No. 11, p 4551-4553

25 Nano Reinforcements of bio-based polymers: The hope and the reality. Mohanty, Amar K.; Drzal Lawrence T.; Misra, Manjusri. Abstracts of Papers, 225th ACS National Meeting, March 23-27, 2003

26 Recent development in nanocomposites. Nippon Hoso Gakkaishi, 2000, Vol. 9, No. 3, p. 167-171.

27 Patent, EP 0458470, Polyamide resin, and polyamide resin compositions

28 Patent, WO 2001009245, Polyester-polyamide blends with reduced gas permeability and low haze

29 Patent, US 3453173, Poly Olefin-Poly Acrylonitrile Laminate \& Method of Making the Same

30 Patent, WO 2006-094167, Preparation of Transparent Multilayered Articles from Polyesters and Homogeneous Polyamide Blends

31 Patent, WO2004089624, Packaging with Water Soluble Barrier Layer

32 Patent, WO 2002020246, Multilayer containers and preforms having barrier properties utilizing recycled material

33 Patent, EP 649737, Polyolefin Multilayer laminates and their uses

34 Patent, EP 365211, Preparation and composition of multilayer high barrier polymer films for packaging materials

35 Patent, JP 59020446 Vinylidene chloride polymers for multilayer packaging materials

36 Patent, US 2008145581, Peelable multilayer laminate for packaging

37 Patent, US 5114795, Multilayered high barrier packaging materials method for the preparation thereof

38 Patent, US 3309330 Coated particles of vinylidene chloride copolymers

39 Patent, US 2824019 An oriented, heat-set polyethylene terephthalate film coated with a plasticized nitrocellulose resin containing a sulfonamide-aldehyde resin

40 Patent, WO2004089624, Packaging with Water Soluble Barrier Layer

41 Patent, US 20050191435, Method for improving the barrier properties of plastic containers

42 Patent, ZA 9700498, Oxyfluorination of a hydrocarbon plastics material and gas barrier packaging

43 Patent, EP 575299, Process for the manufacture of plasma polymer-coated barrier film

44 Patent, JP 57020355, Laminated films

45 Patent, US 4372986, Polyvinyl alcohol-clad shaped article of vinyl chloride resin

46Patent, JP 05295299, Gas-barrier coating compositions and coated articles

47 The measurement of thin poly(vinylidene chloride) coatings on poly(ethylene terephthalate) substrates using fluorescence microscopy, Polymer Testing, 1991, vol. 10, No. 3, 205-219

48 Patent, WO 99/20462 Barrier-Coated Polyester

49 Patent, US 4363840 Packaging films Sheets \& Blown Or Molded Hollow Bodies

50 Patent, US 4544698 Polymer Coating Composition \& Its Use In Manufacture Of Layered Packaging

51 Patent, US 3862284, Process for producing blow molded thermoplastic articles having barrier properties

52 Patent, US 5932304, Barrier layer composition for polyolefin bodies

53 Patent, US 5006381, Ungelled polyamine-polyepoxide resins 
54 Patent, US 5008137, Barrier coatings

55 Patent, US 4515836, Process for coating substrates with aqueous polymer dispersions

56 Poster Presentation, 2008 DOE Hydrogen Program - H2 Tank Manufacturing Optimization, Qiang Liu, et. al., DOE-Annual Merit Review meeting, Washington, D.C., June 2008

57 R. J. Walter and W. T. Chandler, Effects of High-Pressure Hydrogen on Metals at Ambient Temperature: Final Report (NASA CR-102425), Rocketdyne (Report \# R-7780-1) for the National Aeronautics and Space Administration, Canoga Park, CA, February 1969

$58 \mathrm{~N}$ Bandyopadhyay, J Kameda and CJ McMahon Hydrogen-Induced Cracking in 4340-Type Steel: Effect of Composition, Yield Strength, and H2 Pressure, Metallurgical Transactions A, vol. 14A, 1983, p. 881-888

59 GC Story, Hydrogen Assisted Cracking of a low Alloy Steel - Pressure, Temperature and Yield Strength Effects on the Threshold Fracture Toughness, PhD dissertation, Univ. of California-Davis, 1980

60 WG Clark, Effect of Temperature and Pressure on Hydrogen Cracking in High Strength type 4340 Steel, Journal of Materials for Energy Systems, vol. 1, 1979, p. 33-40

61 RJ Walter and W. T. Chandler, Influence of Gaseous Hydrogen on Metals Final Report, NASA-CR-124410, NASA, 1973

62 BP Somerday, JE Smugeresky and JA Brooks. Hydrogen-assisted fracture in LENS-fabricated 316 stainless steel. Hydrogen effects on material behavior and corrosion deformation interactions. Warrendale PA: TMS, p. 499-508, 2003

63 Jewett, R.P. Hydrogen Environment Embrittlement of Metals. NASA CR-2163, 1973

64 C. San Marchi, Technical Reference on Hydrogen Compatibility of Materials, SAND2008-1163, Sandia National Laboratories, Livermore, CA 94550, 2008

$65 \mathrm{MO}$ Speidel. Hydrogen Embrittlement and Stress Corrosion Cracking of Aluminum Alloys. Hydrogen Embrittlement and Stress Corrosion Cracking. American Society for Metals (1984) p. 271-296

66 PM Ordin. Safety Standard for Hydrogen and Hydrogen Systems: Guidelines for Hydrogen System Design, Materials Selection, Operations, Storage, and Transportation. Office of Safety and Mission Assurance, National Aeronautics and Space Administration, Washington DC, 1997

67 GM Bond, IM Robertson and HK Birnbaum. Effects of hydrogen on deformation and fracture processes in highpurity aluminum. Acta Metallurgica et Materialia, Vol. 36, 1988, p. 2193-2197

68 PJ Ferreira, IM Robertson and HK Birnbaum. Hydrogen effects on the character of dislocations in high-purity aluminum. Acta Materialia, Vol. 47, No. 10, 1999 P. 2991-2998

69 G. Han, J. He, S. Fukuyama and K. Yokogawa Effect of strain-induced martensite on hydrogen environment embrittlement of sensitized austenitic stainless steels at low temperatures, Acta mater, vol. 46, 1998, p. 4559-4570 70 J. Qian, J. Chen, J. Chen, Z. Xu, W. Wang and C. Pan Corrosion of austenitic stainless steel in liquid lithium. Journal of Nuclear Materials, Vol. 179-181, 1991, p. 603-606

$71 \mathrm{JA}$ Brooks and AW Thompson. Microstructure and Hydrogen Effects on Fracture in the Alloy A-286. Metallurgical and Materials Transactions A, Vol. 24, No. 3, 1993, p. 1983-1991

72 PS Chen, B Panda and BN Bhat. NASA-HR-1, a New-Hydrogen-Resistant Fe-Ni Base Superalloy. Proceedings of the fifth International Conference on the Effect of Hydrogen on the Behavior of Materials: Hydrogen Effects in Materials, 1994, p. 1011-1019 